\title{
Sciences sociales et postcommunisme. La sociologie polonaise des élites politiques (1990-2000)
}

In: Revue d'études comparatives Est-Ouest. Volume 31, 2000, N². pp. 49-100.

\begin{abstract}
The meeting between a political phenomenon (the role played by political elites in forming the new regimes in central Europe) and a sociological one (the extent of sociological studies of elites in this region) calls for reading this literature in connection with the political processes that sociologists claim to observe from the outside. Centered around Poland, this critical review of all writings on elites in sociology and political science reports on the emergence of this topic as a surprising new paradigm in scientific inquiry, even though its theoretical underpinnings and methodology run back to the Communist era. Two main kinds of studies are distinguished by the author: "sociographies" of political personnel and qualitative research ; but they share characteristics such as an ambiguous use of certain theoretical resources and focalization on the national dimension of political phenomena.
\end{abstract}

\section{Résumé}

La rencontre d'un phénomène politique - le rôle joué par les élites politiques dans la formation des nouveaux régimes en Europe centrale - et d'un phénomène sociologique - l'ampleur de la production sociologique sur les élites dans cette région - incite à lire la littérature scientifique sur les catégories dirigeantes en relation avec les processus politiques qu'elle prétend, du dehors, observer. Centrée sur la Pologne, cette revue critique de l'ensemble des travaux de sociologie et de science politique sur les élites se propose de rendre compte de l'émergence d'un objet d'investigation scientifique qui, s'il trouve des racines théoriques et une filiation méthodologique dans le régime précédent, surprend par sa nouveauté "paradigmatique". L'auteur distingue deux familles principales de recherche (des sociographies de personnels politiques d'une part, des analyses qualitatives de l'autre) mais qui partagent des traits communs, comme par exemple l'usage ambigu de certaines ressources théoriques et la focalisation de la majorité des travaux sur les dimensions nationales des phénomènes politiques.

Citer ce document / Cite this document :

Heurtaux Jacques. Sciences sociales et postcommunisme. La sociologie polonaise des élites politiques (1990-2000). In: Revue d'études comparatives Est-Ouest. Volume 31, 2000, N². pp. 49-100.

doi : $10.3406 /$ receo.2000.3026

http://www.persee.fr/web/revues/home/prescript/article/receo_0338-0599_2000_num_31_2_3026 
Revue d'études comparatives Est-Ouest, 2000, vol. 31, no 2, pp. 49-100

\title{
SCIENCES SOCIALES ET POSTCOMMUNISME. LA SOCIOLOGIE POLONAISE DES ÉLITES POLITIQUES (1990-2000)
}

\author{
Jérôme HEURTAUX*
}

\begin{abstract}
RÉSUMÉ : La rencontre d'un phénomène politique - le rôle joué par les élites politiques dans la formation des nouveaux régimes en Europe centrale - et d'un phénomène sociologique - l'ampleur de la production sociologique sur les élites dans cette région - incite à lire la littérature scientifique sur les catégories dirigeantes en relation avec les processus politiques qu'elle prétend, du dehors, observer. Centrée sur la Pologne, cette revue critique de l'ensemble des travaux de sociologie et de science politique sur les élites se propose de rendre compte de l'émergence d'un objet d'investigation scientifique qui, s'il trouve des racines théoriques et une filiation méthodologique dans le régime précédent, surprend par sa nouveauté "paradigmatique". L'auteur distingue deux familles principales de recherche (des sociographies de personnels politiques d'une part, des analyses qualitatives de l'autre) mais qui partagent des traits communs, comme par exemple l'usage ambigu de certaines ressources théoriques et la focalisation de la majorité des travaux sur les dimensions nationales des phénomènes politiques.
\end{abstract}

ABSTRACT : The meeting between a political phenomenon (the role played by political elites in forming the new regimes in central Europe) and a sociological one (the extent of sociological studies of elites in this region) calls for reading this literature in connection with the political processes that sociologists claim to observe from the outside. Centered around Poland, this critical review of all writings on elites in sociology and political science reports on the emergence of this topic as a surprising new paradigm in scientific inquiry, even though its theoretical underpinnings and methodology run back to the Communist era. Two main kinds of studies are distinguished by the author: "sociographies" of political personnel and qualitative research ; but they share characteristics such as an ambiguous use of certain theoretical resources and focalization on the national dimension of political phenomena.

\footnotetext{
* Allocataire de recherche en science politique à l'Université de Lille II, membre du CRAPS (Centre de recherches administratives, politiques et sociales ; 1, place Déliot, BP 629 - 59024 Lille Cedex. E-mail : jheurtaux@yahoo.fr). Ce travail s'inspire d'une thèse en cours portant sur les formes de légitimation des personnels politiques polonais depuis 1990 . Un grand merci à Frédéric Sawicki pour sa lecture stimulante de versions antérieures de cet article, ainsi qu'à Loïc Blondiaux pour ses précieuses suggestions. Merci aussi aux deux "referees" de la revue d'avoir bien voulu apporter leurs remarques pour améliorer ce texte. Il est dédié à Catherine Leclercq car elle a, de près comme de loin, beaucoup contribué à son achèvement.
} 
«Il faudrait refaire l'Homo Academicus de l'Est et une histoire des élites. Disserter sur la coïncidence entre champ universitaire et champ politique... ».

Rose-Marie Lagrave, Voyage aux pays d'une utopie déchue, Paris, Presses Universitaires de France, 1998.

\section{INTRODUCTION}

En Pologne comme dans la plupart des pays d'Europe centrale, l'émergence du régime démocratique, la pluralisation de la scène politique, l'invention de nouveaux rôles politiques ont bouleversé les modalités de l'observation des catégories dirigeantes. Ces processus récents ont, dans un contexte de renouveau et de développement des sciences sociales, accru la curiosité sociologique pour les personnels politiques. Les élites politiques y forment désormais un objet de recherche à part entière. Si l'on en croit la riche production éditoriale qui leur est consacrée, cet objet a bel et bien conquis ses titres de noblesse scientifique : pas moins de huit ouvrages collectifs ont été publiés sur ce sujet en Pologne depuis 1992 !

Comment étudie-t-on les élites ? Quelles questions se pose-t-on à leur propos ? Quels enseignements, notamment théoriques, inférer des résultats de ces recherches ? Ces interrogations justifient à plus d'un titre que l'on se livre à une revue commentée de la littérature scientifique sur les élites polonaises, et ce d'autant plus que les bilans des recherches sur l'Europe centrale se limitent la plupart du temps à des balayages rapides de l'ensemble d'une discipline 1. Ils prennent tout leur sens dans le cas des élites si l'on considère le potentiel critique que contient toute sociologie du personnel politique. L'enjeu est particulièrement d'importance dans le contexte de formation d'un nouveau régime dans la mesure où les sciences sociales contribuent à désigner, normaliser et légitimer les réalités politiques 2 . Surveillée par les dirigeants, la production sociologique sur les élites est à la charnière de l'observation et de l'implication de la science et de la politique.

1. Les sociologues polonais se penchent régulièrement sur l'histoire de la sociologie et ses rapports au pouvoir communiste (lire par exemple PODGORECKI, 1991 et le numéro de Polish Sociological Review, 1998). Concernant la science politique, voir Politologia w szkolnictwie wyzszym $w$ Polsce. Studia i materialy (La politologie dans l'enseignement supérieur en Pologne. Études et matériaux), 1997. Notons cependant, sur l'étude des élites, l'intéressante synthèse de Jacek Wasilewski, qui offre un point de vue endogène sur l'historiographie polonaise (WASILEWSKI, 1996), ainsi que la thèse et l'article d'Irmina Matonyte, dans la RECEO sur les modes d'analyse des élites économiques dans les pays ex-soviétiques (MATONYTE, 1998 et 1999). Même si la sociologie polonaise ne ménage pas ses efforts pour être lue à l'étranger (l'Association polonaise de sociologie publie en anglais chaque trimestre la Polish Sociological Review), les traductions françaises ou anglo-saxonnes de travaux polonais sont rares (dans le domaine des élites, elles se limitent aux recherches menées par des équipes internationales associant des Polonais). Le développement des sciences sociales est aussi un combat financier et politique. À ce titre, les bilans historiographiques servent à identifier les carences et les limites de la recherche et, pourquoi pas, à susciter une coopération entre nations (LAGRAVE, 1998).

2. Elles contribuent par exemple aux débats tout autant sémantiques que politiques concernant les formes légitimes de représentation des démocraties populaires (sur la RDA, voir LUDTKE, 1998). 
L'examen de l'historiographie suppose dans un premier temps de reconstituer la genèse de l'apparition de ce nouvel objet dans les sciences sociales polonaises. Alors qu'en Europe occidentale, les élites politiques constituent aujourd'hui un objet de recherche parfaitement légitime, doté d'une longue histoire de confrontations théoriques et de nombreuses enquêtes empiriques 3 , elles sont une préoccupation récente des sciences sociales d'Europe centrale. Frappé $d$ 'anathème par le régime communiste, cet objet ne devient scientifiquement correct que dans les premières années de formation du nouveau régime. Il demeure d'ailleurs illégitime aux yeux de certaines fractions de la société polonaise qui refusent de voir dans leurs représentants élus de véritables dirigeants 4 . Le présent article se contente d'illustrer son émergence en tant qu'élément de contexte de la recension. L'étude de l'itinéraire d'un objet de recherche supposerait, en effet, par exemple de mesurer les effets de l'histoire des disciplines et de leur découpage sur les dénominations successives de l'objet et les méthodes utilisées.

La lecture de l'ensemble des travaux invite dans un second temps à présenter leurs orientations théoriques, leurs objectifs et leurs principaux résultats. On peut distinguer deux veines fort différentes. Bien qu'elles soient mobilisées au service de démonstrations empiriques très distinctes, les études morphologiques forment un premier type. Elles constrastent avec les orientations données au second courant de recherches. En dépit de son hétérogénéité, celui-ci inclut les problématiques en termes de métier politique et d'institutionnalisation des rôles politiques. La très nette focalisation des chercheurs sur les élites nationales incite enfin à interroger les raisons de la marginalisation de la dimension locale des objets politiques en Pologne même s'il existe des recherches sur le leadership local.

3. La diffusion des ouvrages des "élitistes" italiens, Pareto et Mosca, la lecture de Max Weber, de Joseph Schumpeter ou de Raymond Aron, 1'importation des travaux américains de Mills ou de Dahl et l'usage empirique de ces ressources théoriques ont progressivement contribué à doter les analyses consacrées aux classes dirigeantes du statut de l'évidence. Le champ d'étude s'est largement étoffé où l'on distingue les analyses sociographiques des personnels politiques, l'étude de leur professionnalisation, les approches en terme de métier politique, etc. En France par exemple, le nombre des travaux portant sur les élites politiques est impressionnant (SAWICKI, 1999 ; LÉVÊQUE, 1996).

4. Certaines de ces opinions s'appuient sur une définition exigeante des élites. Il ne suffit pas d'occuper une position institutionnelle ou de détenir n'importe quel mandat électif. L'appartenance à la catégorie "élites" renvoie à la détention de qualités particulières : les élites dans cette acception sont d'abord un groupe d'individus se distinguant par leurs expériences politiques et participant aux processus décisionnels. Sur 435 étudiants de l'Institut de science politique de l'Université Marie Curie-Sklodowska de Lublin interrogés en octobre 1992 par deux étudiantes de la Faculté de politologie, seuls $61 \%$ d'entre eux considèrent ainsi qu'Hannah Suchocka, alors Premier ministre, est membre de l'élite politique. Lech Walesa, président de la République depuis presque deux ans, appartient à l'élite politique pour seulement $32,5 \%$ de l'échantillon. Pour $66,6 \%$ des interrogés seulement, il existe bien des élites politiques en Pologne (PrZeor-PastuszaK \& SURMaCZ, 1992). La divulgation de certaines pratiques clientélistes et du fait que les gouvernements postcommunistes et les gouvernements issus de l'opposition démocratique étaient corruptibles ont également renforcé les opinions assimilant les catégories dirigeantes à des individus corrompus, c'est-à-dire, dans cette perspective, à des non-élites. Certaines formes de corruption politique ont déjà été décrites (KAMINSKI, 1997). 
Nous étudierons ici l'ensemble des travaux empiriques consacrés aux personnels politiques polonais, sans exclure les analyses du changement de régime dans lesquelles l'élite n'est qu'un des aspects de la démonstration. Afin de rendre compte de l'hétérogénéité théorique et méthodologique de la recherche sur les catégories dirigeantes, sont regroupées sous ce label des analyses très différentes : la catégorie "élites politiques " hébergera ici les travaux se rattachant explicitement au champ de recherche sur les élites mais aussi les études portant sur la profession politique, le leadership local, etc. La diversité sémantique ne doit pas faire obstacle à la démarche. La catégorie appréhendée est cependant exclusivement constituée des responsables politiques, ce qui n'empêche pas d'évoquer d'autres types d'élites sociales 5 .

1. UN ENJEU INDISSOCIABLEMENT POLITIQUE ET SOCIOLOGIQUE : DE L'ÉVITEMENT COMMUNISTE DES ÉLITES À LEUR ÉMERGENCE RÉCENTE DANS LES SCIENCES SOCIALES POLONAISES

\subsection{UN OBJET INTROUVABLE DANS LA RÉPUBLIQUE POPULAIRE DE POLOGNE}

Pour les sciences sociales comme pour tout autre sujet en rapport avec la période dite du socialisme réel, l'usage du schème totalitariste, en vertu duquel le monolithisme se serait imposé dans tous les aspects de la vie sociale, ne permet pas de rendre compte des rapports complexes qui lient les sociologues et le pouvoir. Il faut pourtant reconnaître que le Parti ouvrier unifié polonais (POUP) est parvenu, avec le concours plus ou moins actif des chercheurs, à imposer à la sociologie des thèmes légitimes et à disqualifier certains autres. Les élites politiques constituent un non-objet dans les sciences sociales polonaises pendant la période, dans la mesure où jamais il n'est construit sociologiquement comme objet de recherche empirique en tant que tel. C'est un domaine où les distorsions entre les principes idéologiques et la réalité sont en effet susceptibles d'être mises en évidence de manière significative. La question du rapport entre le recrutement social des catégories dirigeantes et la composition de la société polonaise, celle de l'inégal accès aux ressources politiques ne sont jamais clairement posées. C'est pourquoi, pour rendre compte de la manière dont la sociologie polonaise de cette époque appréhende ou non le problème de ses élites, il est nécessaire d'élargir la prospection à des travaux qui ne relèvent pas de ce que l'on pourrait appeler « l'élitologie ».

5. Si nous avons choisi ici de privilégier les études consacrées aux élites politiques, c'est-àdire, dans une acception institutionnelle, aux personnels politiques des institutions démocratiques (Parlement, gouvernement, assemblées locales, etc.), il faut bien prendre en compte le fait que la valorisation de l'entrepreneuriat économique dans le contexte de l'émergence d'une économie de marché a contribué à déplacer l'attention des observateurs vers les élites économiques et d'autres élites sociales (WESOLOWSKI, 1999). Si notre préoccupation était de localiser les "ressources de pouvoir" les plus valorisées dans une société postcommuniste, nul doute que notre exploration de la production sociologique serait élargie à la sociologie économique et de la structure sociale. 
Le non-intérêt pour les élites est théorisé en des termes euphémisés. Certains politologues, parmi les plus intégrés au régime communiste, n'hésitent pas à se débarrasser habilement du terme d'élites. Ainsi Jerzy J. Wiatr distingue-t-il en 1973 les notions d' « élites politiques » (political elites) et de « leadership politique » (political leadership) (Wiatr, 1973). Le leadership est une «fonction sociale » inhérente à toute société. Les élites existent pour l'auteur lorsque « la distribution des ressources valorisées est si sensiblement inégale que certaines minorités se distinguent considérablement du reste du groupe social par la haute concentration d'une ou plusieurs de ces ressources $\gg$. Le leadership politique devient une élite si l'on peut empiriquement démontrer que l'accès au leadership politique est inégalement distribué dans la société : «Les leaders politiques constituent une élite politique quand (a) la distribution du pouvoir au sein du groupe [community] est sensiblement inégalitaire, une minorité ayant un plus grand pouvoir que le reste du groupe ; et (b) l'accès au groupe leadership est limité de telle manière que les leaders et les suiveurs [followers] ne changent pas facilement de rôle »(Wiatr, 1973, p. 94). Ainsi parvenir à démontrer l'existence d'une circulation des élites entre les milieux dirigeants et le peuple 6 , c'est dans cette conception nier l'existence même des élites. Le tour de main sémantique est un coup de force politique.

Le problème élitaire n'est en effet jamais posé dans les termes classiques durant la période communiste. Les rapports des élites à la démocratie, les mécanismes de recrutement des catégories dirigeantes ou les ressources et les privilèges dont elles disposent n'apparaissent pas dans les questionnements de « la science politique ». Jacek Wasilewski remarque qu' « aucune étude, s'appuyant sur la théorie des élites et établissant l'existence des élites, surtout politiques, n'est conduite en Pologne, dans les structures officielles de la science, avant la fin des années quatre-vingt » (Wasilewski, 1996). Cela ne signifie pas qu'aucune réflexion sur le pouvoir ou les inégalités sociales n'est menée avant cette date. En réalité, ce sont les sociologues qui pourvoient aux carences de la politologie. La sociologie stalinienne, pour laquelle il n'existe que deux classes, la classe ouvrière et la paysannerie, est remise en cause dès le début des années soixante. Les analystes de « la stratification sociale », à l'image de Stanislaw Ossowski ou Wlodzimierz Wesolowski, utilisent désormais la profession en plus de la classe dans leurs analyses (Ossowski, 1971 ; Wesolowski, 1966 ; Slomczynski \& Wesolowski, 1977 ; Kurczewski, 1998). Pour le sociologue hongrois Ivan Szelenyi, les analyses de la stratification sociale qui se développent en Europe

6. Ce que Jerzy J. Wiatr affirme d'ailleurs plus loin à l'appui des travaux de R. B. Farrel : «Les études sur le leadership politique communiste semblent indiquer qu'avec le temps, de la première génération (révolutionnaire) à la seconde (postrévolutionnaire), les leaders politiques sont (i) plus semblables aux autres groupes professionnels, et notamment aux chefs d'entreprise, en ce qui concerne leur éducation, le recrutement par des canaux établis de promotion. la carrière bureaucratique, etc. ; (ii) plus semblables au reste de la population, en termes de parcours social ainsi, partiellement, qu'en raison du pourcentage élevé et disproportionné de diverses minorités (ethniques, religieuses, régionales, etc.) parmi les élites révolutionnaires " (WIATR, 1973, p. 98). 
centrale pendant cette période enrichissent l'analyse : « En distinguant les "cols blancs" des "cols bleus", les travailleurs manuels des employés, les membres des professions intellectuelles des intellectuels professionnels occupant des positions de leaders (ce terme euphémistique est utilisé pour désigner les bureaucrates de rang élevé dans le Parti et dans l'État), cette analyse pouvait statistiquement démontrer ce qui sépare les "cols blancs", et spécialement l'élite au pouvoir, des véritables ouvriers » (Szelenyi, 1978). L'auteur indique toutefois que ces analyses échouent à théoriser à partir des résultats, en raison notamment de l'incapacité de définir clairement les titulaires des postes dirigeants : « De nombreux sociologues empiriques utilisent le terme "classe ouvrière" pour décrire les travailleurs manuels, ceux qui sont directement impliqués dans le "procès de production", mais ils évitent soigneusement d'utiliser un terme structurel pour la "moitié supérieure" de la hiérarchie sociale. On les appelle "les individus occupant une position plus élevée dans la hiérarchie sociale", "les groupes de revenu plus élevés", "les groupes sociaux supérieurs" et personne ne semble prêter attention à la signification théorique de cette terminologie » (ibid., pp. 63-64). Par ailleurs, il faut bien convenir que la plupart des auteurs-clés de l'école de la stratification sociale, tel que Wlodzimierz Wesolowski, ont longtemps conservé une problématique marxiste. La dimension politique de la stratification sociale, c'est-à-dire l'inégalité des individus et des groupes sociaux à l'égard du pouvoir en régime socialiste est ainsi à peine évoquée dans la recherche sociologique, de crainte de trop s'éloigner du dogme 7. Les analyses d'inspiration trotskiste, défendues par des intellectuels contestataires, dénoncent de manière nettement plus radicale la différenciation sociale entre les élites et le peuple et l'échec du projet égalitariste d'abolition des classes. Milovan Djilas décrit dès 1957 « la nouvelle classe » (Djilas, 1957) tandis qu'en Pologne, deux intellectuels, Jacek Kuron et Karol Modzelewski, rédigent en 1964 leur Lettre ouverte au Parti Polonais, dans laquelle ils distinguent, au sein de la classe dirigeante, la «bureaucratie politique centrale », la véritable élite politique du pays, de la vaste technocratie (Kuron \& Modzelewski, 1968) 8.

7. Georges Mink a par exemple très bien montré qu'en dépit de l'évolution des questionnements théoriques des sociologues de la stratification, de la multiplication des approches behavioristes, de la complexification des descriptions des structures sociales et de la sophistication des outils mobilisés, les sociologues restaient pour la plupart prisonniers d'une approche politique des réalités qu'ils étudiaient (MINK, 1982b). Mink l'explique en partie par la très forte dépendance de la sociologie polonaise à l'égard du pouvoir, qui s'exprime notamment par le monopole étatique de distribution des ressources (financières et symboliques) dans la communauté scientifique et par la valorisation du rôle du sociologue expert (MINK, 1982a et 1982b). Janina Markiewicz-Lagneau explique le renoncement des sociologues aux problématiques les plus audacieuses par un facteur socio-psychologique : «Les quelques indices que nous avons fragmentairement suggèrent moins l'hypothèse machiavélienne d'un pouvoir qui découragerait toute étude de son fondement par peur d'être contesté que celle selon laquelle les gouvernés ne sont guère disposés à développer une conscience réflexive de leur état de gouvernés » (MARKIEWICZ-LAGNEAU, 1969).

8. Sur ces courants et leur critique, se reporter à KENDE \& STRMISKA, 1984. 
Le constat qui vient d'être dressé ne doit cependant pas conduire à surestimer l'illégitimité politique de la problématique élitaire. Certains théoriciens des élites sont lus et commentés, à l'image de Wright Mills par exemple, introduit très tôt en Pologne. Il faut cependant reconnaître que c'est davantage pour ses aspects théoriques et pour la formidable critique de la société capitaliste qu'elle recèle, que pour ce qu'elle contient de potentiellement heuristique pour la société polonaise, que L'élite du pouvoir est diffusée 9 . Le paradoxe frappant entre la vigueur du positivisme en Pologne et l'absence d'enquêtes empiriques sur les élites souligne fortement l'illégitimité d'une approche sociologique des élites communistes. Il faut attendre les mouvements d'opposition ouvrière, soutenus par des membres de l'intelligentsia, pour que se renforce à partir des années soixante-dix l'intérêt social pour les élites. Ces initiatives contribuent à élargir l'horizon de la recherche, bien que celle-ci se développe à l'extérieur de l'Université. Même si on lit les théoriciens classiques des personnels politiques, peu de recherches empiriques voient le jour, hormis sur des objets périphériques. Comme l'explique Wasilewski, « il s'est formé toute une série de recherches sur les élites intellectuelles et artistiques, sur le pouvoir local, l'administration centrale et gouvernementale, la bureaucratie régionale ou les directeurs d'entreprise (...) [Cela conduit] à la conclusion qu'au moment de la chute de l'ancien régime, les sciences sociales en Pologne étaient plutôt préparées - mais très certainement de manière insuffisante - à analyser le rôle des élites dans les changements institutionnels » (Wasilewski, 1996, p. 220).

\subsection{LES ÉLITES : UN OBJET MARGINAL DE LA « SCIENCE DES TRANSITIONS »}

Avant d'examiner la sociologie polonaise des élites, il convient de relativiser son importance par une lecture rapide et partielle de la littérature de sociologie et de science politique sur les sociétés d'Europe centrale depuis 1990. Les analyses menées dans l'optique transitologique accordent en effet peu d'attention à

9. La notice nécrologique publiée en 1962 par Julian Hochfeld en hommage à Wright Mills qui venait de disparaître est emblématique de l'ambiguiité avec laquelle on traite le problème des élites en Pologne (HochFeld, 1962). L'application avec laquelle Hochfeld cherche à valoriser son confrère décédé en insistant sur ses attributs les plus légitimes dans l'optique communiste de l'époque - Mills est américain mais patriote, et de surcroît pacifiste ; il n'est certes pas communiste mais il est toujours « du côté du faible, de l'opprimé, de l'exploité, contre l'élite du pouvoir »-peut susciter deux lectures contradictoires. La première est de considérer l'exercice comme une tentative un peu naïve de faire de Mills un compagnon de lutte, un camarade non déclaré, en montrant que les préoccupations d'une certaine sociologie américaine épousent celles de la sociologie polonaise. La seconde revient, à l'inverse, à considérer ce texte comme une tentative implicite de parfaire l'introduction de la problématique élitaire en Pologne. Quelle que soit en définitive l'intention du sociologue marxiste, l'essentiel est de noter que, dans les deux cas, l'acte par lequel on légitime la lecture de Mills suppose un travail de normalisation du chercheur américain aux catégories marxistes de l'intellectuel, ainsi qu'une occultation délibérée du potentiel heuristique que son œuvre pourrait contenir. Hochfeld évoque en effet à peine l'ouvrage majeur de Mills et il élude constamment le potentiel critique que ce dernier contient dans le contexte de la société communiste bureaucratique. 
cette question. Par contraste avec le fort intérêt porté aux élites dans les sciences sociales polonaises, la revue de la production sociologique « occidentale » sur les changements politiques des pays ex-communistes, et particulièrement sur la Pologne depuis 1990, montre la relative marginalité des études sur les personnels politiques. Les sciences sociales se sont en effet d'abord intéressées aux causes de l'effondrement du système communiste, avant d'analyser le passage d'un système à un autre. Ce sont les processus généraux de ce qu'ils appellent « la transition démocratique » qui mobilisent d'abord l'attention des chercheurs. Retournant avec profit la critique marxiste du capitalisme, les uns considèrent que le système communiste a implosé par le fait de ses propres contradictions 10 . Sans centrer l'analyse sur les élites, d'autres estiment à l'inverse que l'effondrement des régimes communistes est à mettre à l'actif des dirigeants communistes eux-mêmes qui en auraient précipité la fin 11 . Un dernier courant met en exergue l'action déterminante de ce que l'on appelle la «société civile ». Il se traduit par la volonté de placer l'acteur social au centre de l'interprétation sociologique. Sabrina Ramet interprète par exemple l'arrivée au pouvoir de Gorbatchev comme le couronnement de l'action des mouvements sociaux (le syndicat Solidarité en Pologne, la dissidence intellectuelle en RDA et Tchécoslovaquie, le féminisme en Yougoslavie, le rock, l'engagement religieux, etc.) participant tous d'un processus de modernisation opposé au communisme (Ramet, 1992 ; Tismaneanu, 1992 ; Molnar, 1990 ; Burawoy \& Lukacs, 1992). Une ligne de fracture traverse ces dernières recherches autour de la désignation du groupe social qui aurait joué le rôle déterminant dans les mouvements démocratiques. Les recherches valorisant l'action des ouvriers dans le syndicat Solidarité se distinguent de celles qui mettent l'accent sur le rôle joué par les intellectuels 12 .

Un second ensemble de questions émerge au sein des sciences sociales dans les premières années du postcommunisme. Il s'agit d'analyser les évolutions sociales, économiques et politiques des sociétés d'Europe centrale, considérées comme des sociétés en transition entre un système de type soviétique et un régime pluraliste de démocratie libérale. Dès lors, les chercheurs s'intéressent principalement au processus général de transition, ainsi qu'aux acteurs sociaux et poli-

10. Pour Bartlomiej Kaminski par exemple, les racines de l'effondrement ne sont ni économiques ni politiques, mais d'ordre institutionnel et systémique (KAMINSKI, 1991 ; voir aussi dans une perspective proche, l'ouvrage de son homonyme, Kaminski, 1992). Pour d'autres chercheurs, la cause de la désintégration de ces systèmes se trouverait plus précisément dans la nature des politiques économiques (CLARK \& WILDAVSKI, 1990).

11. Voir Kende \& Smolar, 1990 ; OfFe, 1992 et StaniszKis, 1991. Ce phénomène est patent par exemple en Bulgarie ou, selon la sociologue Boriana Dimitrova, « le changement » du système n'était possible que sous le contrôle du parti-État, « et notamment de son aile économique », en raison de « la faiblesse traditionnelle des structures économiques et politiques autonomes et de l'absence totale d'une société civile à l'époque du socialisme » (Dimitrova, 1996).

12. David Ost met par exemple l'accent sur les intellectuels du syndicat ; ces derniers seraient parvenus à imposer aux membres de Solidarité leur propre stratégie et notamment une orientation néo-corporatiste (OST, 1990). Romain Laba, à l'opposé, analyse les grèves des chantiers navals de Gdansk en 1970 comme l'origine ouvrière du mouvement de contestation du régime qui s'actualise en 1980 autour de Solidarité (LABA, 1991). Voir également GoodwyN, 1991. 
tiques qui émergent au cours de la période 13. Les analyses qui privilégient les mutations de structure sur les motivations des acteurs semblent plus nombreuses que les analyses des processus de transition par l'étude des actions individuelles. Les synthèses à ambition théorisante sont légion et les comparaisons internationales entre certaines régions politiques du monde, d'une part, entre les sociétés désoviétisées, d'autre part, ne sont pas rares. Le politiste allemand Claus Offe propose ainsi de spécifier les transitions d'Europe de l'Est des transitions intervenues dans d'autres zones du monde et dans d'autres périodes, comme dans les « démocraties d'après guerre », les récentes démocraties méditerranéennes et celles d'Amérique du Sud 14. Pour les principaux travaux appartenant à la « transitolo-

13. Les études de la transition peuvent, selon Herbert Kitschelt, être divisées en deux camps théoriques. Les analyses appartenant au premier se concentrent sur les changements structuraux qui affectent les sociétés postcommunistes, les autres insistent plutôt sur les motivations et les comportements des acteurs ainsi que sur le processus de changement lui-même. Les chercheurs qui se réclament du premier courant d'analyse privilégient les forces structurelles sur le rôle des acteurs. Cf. les réflexions autour des rapports entre la démocratisation et la libéralisation (Hirschman, 1995 ; PrZewORSKI, 1991 ; Diamond \& PlatTNer, 1995). Moins récemment, voir également Rozman, 1992 ; Hovacs \& TARDOS, 1992. Pour un essai de théorisation d'une politique économique de la transition, lire HaGgard \& KaUfMAN, 1995. Enfin, pour une analyse économique de la transition en Pologne, détaillée par secteurs d'activité, se reporter à BLAZYCA \& RAPACKI, 1991. Pour une analyse différente, cf. KENDE, 1996. Les chercheurs appartenant au second courant étudient des acteurs politiques élaborant des stratégies, en interaction avec les autres agents. La division proposée par Kitschelt bouleverse la distinction faite habituellement entre des sociologues, qui réduisent l'autonomie des personnes, et des économistes, porteurs de modèles de rationalité pour des acteurs stratégiques : en proposant une macro-économie du changement, ceux-ci appartiennent de fait au schéma structuraliste ou macro-social. C'est finalement autour de la notion de choix que se distinguent les deux écoles : "Ce qui est en jeu entre les études orientées sur les structures et celles privilégiant les processus du changement de régime politique est une distinction plus fondamentale concernant le concept de choix dans l'action politique lui-même. Pour les structuralistes, les choix représentent des calculs à la lumière des préférences données et des contraintes institutionnelles. Pour les chercheurs privilégiant les processus, les choix sont pris dans un contexte de redéfinition continue des perceptions des acteurs, de leurs préférences et des contraintes » (KITSCHELT, 1992, p. 1028).

14. Deux éléments viendraient en effet particulariser le processus de transition en Europe de l'Est. Il s'agirait, d'une part, de la question territoriale qui, selon C. Offe, engendre des conflits de minorité et de nationalités et des aspirations sécessionnistes et, d'autre part, surtout de la question économique : «À la fin du socialisme, la tâche supplémentaire est de réformer l'économie, (...) [d'organiser] le transfert de moyens de production qui appartenaient à l'État à d'autres formes de propriété et, à cet effet, la création d'une classe entièrement nouvelle d'entrepreneurs et de propriétaires par décision et justification politiques et par le biais d'acteurs politiquement visibles. L'installation révolutionnaire d'une classe d'entrepreneurs (...) représente une tâche qu'aucune des transitions précédentes n'a eu à accomplir » (OFFE, 1992, p. 925). On peut aussi citer l'ouvrage collectif dirigé par Edmund Wnuk-Lipinski qui, s'il n'a pas d'ambition comparative, représente néanmoins une tentative d'élaborer une théorie du processus de transition dans les sociétés d'Europe centrale (WNUK-LIPINSKI, 1995a ; WNUKLIPINSKI, 1995b ; STANISZKIS, 1995 ; PACZKOWSKI, 1995 ; ROSZKOWSKI, 1995). Certains auteurs proposent des interprétations très différentes de la transition, qui les rendent difficilement classables. Patrick Michel et Marcyn Frybes notamment font une lecture non conformiste des changements intervenus en Pologne durant une transition que les auteurs refusent de définir comme un processus positif de réformes économiques et politiques, mais comme un terme qui désigne « le laps de temps nécessaire pour combler le décalage entre réalité et mentalités, pour assurer la coïncidence entre la réalité d'un dégagement du système de type soviétique et des mentalités devant intégrer et s'adapter à cette réalité 》 (FrYBES \& MichEL, 1996). 
gie », les élites ne sont qu'une des variables expliquant la consolidation démocratique des nouveaux régimes politiques en Europe centrale (Linz \& Stepan, 1996 ; Crawford \& Lijphart, 1995). Même s'il faut reconnaître une filiation de la plupart d'entre eux et du paradigme de l'acteur rationnel (Hermet, 2000), ce qui n'est pas sans avoir des effet de déplacement de l'attention des chercheurs sur les acteurs des changements et notamment les élites, celles-ci ne sont finalement qu'un facteur d'explication du processus de «transition » et de «consolidation » et ne sont qu'une syllabe dans le langage bruyant des variables 15. Lorsqu'elles sont un élément central de l'explication, comme dans les analyses de Lynn Karl et Schmitter, les élites servent la construction de typologies générales des processus de transition (O’Donnel \& Schmitter, 1993 ; Lynn Karl \& Schmitter, 1991).

L'étude des acteurs politiques et sociaux collectifs et des institutions est privilégiée. Ces acteurs sont en premier lieu les partis politiques et les syndicats. Les partis politiques ont été étudiés sous l'angle de leur institutionnalisation et de la constitution d'un système partisan dans lequel on a très vite cherché puis échoué à placer la plupart des partis sur des axes structurants, différenciant chaque organisation selon son programme économique ou les valeurs qu'elle défend 16 . Le rôle joué par Solidarité dans l'effondrement du régime socialiste et les évolutions du syndicat justifient que l'on se soit plus intéressé à lui qu'aux autres syndicats polonais. Qu'il ait fait l'objet d'une approche sociologique de ses adhérents et lea-

15. J. J. Linz et A. Stepan proposent ainsi de distinguer cinq « arènes interactives » dans lesquelles s'inscriraient les deux processus de «transition » et de «consolidation». Parmi elles, « la société politique », formée de tous les acteurs qui participent aux processus de décision ainsi qu'à la compétition politique, constitue en quelque sorte l'élite politique, entendue au sens large. Au même titre que « la société civile », « l'État de droit », « l'État » et « la société économique ", l'élite est promue au rang d'espace de rencontre entre deux variables dépendantes (la transition et la consolidation) et sept variables indépendantes - dont les plus importantes sont « le degré d'autorité et de légitimité spécifique conservé par l'État 》 (HERMET, 2000) et "l'héritage du régime disparu » (LINZ \& STEPAN, 1996); deux d'entre elles (le type de « leadership » du régime précédent et l'origine des initiateurs du changement) se rapportent aux acteurs (LINZ \& STEPAN, 1996).

16. L'émergence d'une scène politique pluraliste suscite, dans un premier temps, une analyse des origines des partis politiques (MARODY, 1995). D'autres auteurs rendent compte de la structuration de l'espace politique polonais en considérant la constitution du système de partis comme une des modalités de l'institutionnalisation du conflit et du pluralisme (LEWIS, 1994). Certains tentent de représenter intellectuellement ce système sur un axe (WIATR, 1993) ou à l'aide d'un diagramme (WESOLOWSKI, 1993). Tous concluent à la difficulté, voire à l'impossibilité, de cliver nettement le système de partis en fonction de leur programme économique et social et des valeurs qu'ils défendent. Le système partisan polonais serait un non-système (SzKLARSKI, 1993) et sa fragmentation s'expliquerait par l'imparfaite définition des intérêts parfois contradictoires défendus par les partis (GRABOWSKA, 1993). Évoquons également les études d'un parti ou d'une famille partisane. L'adaptation de l'ancien parti unique aux règles pluralistes et sa résurrection rapide sous le manteau social-démocrate ont bien sûr posé la question de la pertinence des modèles ouest-européens pour analyser la nouvelle gauche est-européenne, et l'installation des ex-communistes au pouvoir en 1993 en Pologne a suscité également nombre d'interrogations sur l'identité réelle de cette nouvelle entreprise politique (ZUBEK, 1994 et 1995). 
ders (Blaszkiewicz, Rykowski, Szwajcer \& Wertenstein-Zulawski, 1994), d'une analyse de ses activités politiques (Heyns \& Bialecki, 1991), d'une controverse sur ses origines (Ost, 1990) ou d'une histoire de son influence sur la société polonaise depuis 1980 (Laba, 1991), Solidarité reste, dans la lignée des ouvrages de Jadwiga Staniszkis (Staniszkis, 1984) et de l'équipe d'Alain Touraine (Touraine, Dubet, Wieviorka \& Strzelecki, 1982), une clé pour la compréhension de la situation politique en Pologne (Frybes, 1993). La richesse des questionnements qu'il suscite contribue à atrophier d'autant l'intérêt porté au personnel dirigeant.

\subsection{LES SCIENCES SOCIALES ET LE POSTCOMMUNISME. CURIOSITÉ SOCIALE ET INTÉRÊT SOCIOLOGIQUE POUR LES ÉLITES}

Ce désintérêt relatif pour l'objet «élites politiques » des sociétés postcommunistes dans les sciences sociales mondiales contraste fortement avec les préoccupations de la sociologie indigène. L'illégitimité qui frappait l'étude des élites durant la période communiste s'est considérablement atténuée au moment du changement de régime. Les indices de l'émergence d'une nouvelle catégorie doublement politique et sociologique sont nombreux : multiplication des autobiographies des principaux leaders de l'opposition, développement des baromètres de satisfaction des nouveaux gouvernants, etc. L'état de grâce dont bénéficient les nouvelles élites postcommunistes constitue sans aucun doute le premier sujet de discussion dans la communauté scientifique. Issus des milieux de l'opposition dite démocratique au régime communiste, une partie des sociologues font corps avec leurs élites nouvellement élues, épousent leurs succès, leurs doutes et leurs dilemmes. C'est à travers cette identification certaine des élites scientifiques à leur objet, qui finira en divorce dans les années qui suivront, que se comprend l'émergence significative de cet objet dans les sciences sociales polonaises. Nous avons choisi de l'illustrer en insistant sur cette ambiguïté.

Dans sa dernière livraison de l'année 1992, The Polish Sociological Bulletin 17 publie quatorze courtes réflexions de sociologues rédigées en réponse à une enquête menée par le ministre Andrzej Zakrzewski au nom du président Walesa (Polish Sociological Bulletin, 1992). Cent personnes du monde de la science et de la culture polonaises ont en effet été sollicitées en janvier 1992 pour répondre aux trois questions suivantes : «1. De quoi la Pologne et les Polonais ont-ils le plus besoin aujourd'hui ? 2. Quels sont les dangers les plus saillants et les enjeux les plus difficiles ? 3. Qui peut résoudre ces problèmes et comment ? ». L'initiative officielle est justifiée comme suit : «La nation Polonaise a de plus en plus de difficultés à supporter la crise prolongée. La tension augmente. Les gens deviennent de plus en plus aigris. La confiance dans la capacité du Gouvernement, du Parlement et du Président à prendre de bonnes décisions et à les mettre en œuvre effectivement s'affaiblit. Les gens se demandent de plus en plus fréquemment pour combien de temps encore ils devront faire sans, pour combien de temps les hommes politiques seront principalement absorbés par la

17. C'est l'ancien nom de l'actuelle Polish Sociological Review. 
poursuite d'intérêts privés et la scène politique dominée par des disputes personnelles et des querelles inter-partisanes. Les hommes politiques et l'administration d'État devraient proposer des programmes clairs, concertés, constamment réalisables et lisibles pour tous. La situation actuelle dans notre pays exige la coopération des personnes compétentes, de bonne volonté, pour qui les intérêts de la nation prennent le pas sur tous les autres intérêts : c'est aujourd'hui l'enjeu le plus important. Faisons les efforts les plus grands afin de préserver la jeune démocratie de bouleversements et garantir la réalisation graduelle de ses idéaux $\gg 18$.

Les réponses adressées par les sociologues appellent plusieurs commentaires. Le contenu des textes révèle d'abord les représentations qu'ils se font de leurs élites politiques. Pour la plupart des auteurs, les élites politiques, c'est-à-dire les élites gouvernantes et parlementaires, ne sont pas à la mesure des responsabilités qu'elles occupent. Les textes décrivent dans une langue sans concession des élites incompétentes, préoccupées de leurs seuls intérêts, investies dans des querelles internes ou incapables d'élaborer une stratégie politique pour le développement économique de la Pologne. Pis, le clivage « eux-nous », en vogue sous le communisme pour rendre compte du fossé séparant la nomenklatura communiste et le peuple, se perpétuerait sous le nouveau régime. Expression de la défiance de la population à l'égard du pouvoir, le maintien de ce clivage peut en partie s'expliquer, comme cela a été avancé, par l'inefficacité d'une « pédagogie des masses » à l'égard des institutions démocratiques, le peuple resterait prisonnier de schèmes de pensée surannés, voire maintenu dans une forme d'ignorance civique. Personne ne conteste néanmoins tant l'existence que la légitimité du discrédit social qui frappe les catégories dirigeantes. Si la majorité des contributeurs rendent compte de l'existence d'un fossé séparant les élites de la société, celui-ci n'est néanmoins jamais exprimé en terme de non-représentativité sociale des élites.

Les textes nous informent également des conceptions que les sociologues ont « des bons gouvernants ». L'élite que chacun appelle de ses vœux est une élite compétente, issue de préférence de l'intelligentsia, une élite « professionnelle ». C'est une élite réformatrice, qui comprend la nécessité de légiférer avec discernement. C'est surtout une élite qui parvient à euphémiser, voire à nier ses divisions idéologiques, au profit de l'élaboration raisonnée de décisions rationnelles et consensuelles : «La coopération des hommes politiques devrait s'appuyer sur des actions rationnelles et prévisibles et non sur des gestes émotionnels » (Jan Szczepanski). C'est enfin une élite débarrassée des transfuges de la nomenklatura et condamnant les pratiques corruptrices. Ainsi, il n'est que Maria Los pour défendre implicitement une conception différente des élites. En condamnant la

18. Le contexte politique en 1992 est celui d'une crise de confiance à l'égard de Lech Walesa et des gouvernements issus de Solidarité. Le président est en conflit avec le Parlement ainsi qu'avec son propre Premier ministre, Jan Olszewski. L'intention présidentielle est cerlainement alors de chercher parmi les intellectuels une légitimation à son action politique. 
marginalisation politique des femmes, il est vrai quasi absentes des principales institutions représentatives, la sociologue se montre favorable, quoique prudemment, à une élite composée d'individus issus de groupes sociaux au prorata de leur poids dans la société.

Ces enseignements ne doivent pas surestimer l'enjeu posé par les élites. La non-qualification des élites n'est pas pour les sociologues la difficulté principale à laquelle la Pologne est confrontée. Il est cependant intéressant d'analyser le rôle que ces intellectuels prescrivent aux élites dans la transformation du régime - que tous assimilent à la démocratisation politique et la libéralisation économique. Personne ne conteste la nécessité de l'implication des élites dans la transformation. Mais ce sont plus précisément les titulaires des principales charges publiques, en premier lieu le Président de la République, qui ont la responsabilité du changement. Toutefois, l'ensemble des auteurs insistent sur la nécessité d'un gouvernement éclairé par la raison. Tous ne revendiquent pas, à l'instar d'Antonina Kloskowska, la nécessité de former « a supra-party cabinet of professionals ». Cependant tous défendent les bienfaits d'une expertise permanente, quoique sous des formes différentes, menée par l'intelligentsia. Adam Podgorecki décline l'ensemble des acteurs qui pourraient ainsi participer au processus : « À côté des autorités administratives désignées pour cela (...) (a) Le Président (...) la personnification en Pologne du désintérêt (...). Le Parlement (...) ; (b) Des équipes expérimentées de techniciens compétents dans le social, l'organisation, l'économie et la technologie (l'ingénierie sociale humaniste en particulier); (c) Des volontaires ; (d) Des équipes de spécialistes en science informatique, d'inventeurs, d'experts motivés par la possibilité de faire des découvertes socialement utiles... ».

Le rôle dévolu au sociologue dans ce projet est central. Les contributeurs ne se limitent pas en effet à construire une vision normative des dirigeants qu'ils appellent de leurs vœux. Ils contribuent également à prescrire les rôles et les devoirs constitutifs, selon eux, du métier de sociologue. Conformément à une pratique spécifique d'intervention des représentants de cette discipline dans la vie publique que certains invoquent pour légitimer son actualisation - les références à la tradition d'engagement des sociologues est par exemple rappelée par l'un d'entre eux en introduction au dossier 19 -, le sociologue expert et l'ensemble de l'intelligentsia « demeurent le seul groupe capable de transmettre des modèles, des normes et des signaux d'information entre la classe politique et le reste de la société » (Marek Latoszek). On peut être saisi du paradoxe consistant à défendre une tradition d'engagement tout en continuant de revendiquer une position d'extériorité radicale à l'égard du monde social, comme si les activités des sociologues produisaient des effets sociaux et politiques tout en protégeant ces derniers. Cette position est théo-

19. «La profession et l'appellation du sociologue, à la fois dans la tradition sociologique universelle et même plus dans la tradition sociologique polonaise, impliquent le droit moral et intellectuel de participer activement à la vie publique, le droit d'agir en tant qu'autorité, arbitre, prophète, timonier de la vie publique » (Joanna Kurczewska). 
riquement séduisante mais effectivement intenable 20 . Un exemple l'illustre. Convaincue que le discrédit des parlementaires trouve son explication dans un défaut d'information du peuple et non dans les députés eux-mêmes, Maria Los propose par exemple que les travaux consacrés aux élites par l'Académie polonaise des sciences soient utilisés à des fins éducatives (sous la forme d'un programme télévisé) afin de réduire l'ignorance populaire constitutive, selon elle, du mécontentement des Polonais à l'égard de leurs dirigeants. La recherche sur les élites peut aussi contribuer à les légitimer. D'une manière générale, les contributions sociologiques à l'enquête présidentielle sont emblématiques de l'ambiguïté des objectifs que nombre de praticiens des sciences sociales assignent à leurs recherches. Celles-ci ne se limitent pas à la compréhension du monde social, à l'enrichissement de la réflexion théorique. Elles comprennent également une dimension politique plus ou moins explicitée, que confirment, nous le verrons, certaines préoccupations théoriques 21 . Les travaux sociologiques sur les élites doivent être appréhendés avec une prudence particulière comme des textes à la charnière du politique et de la science pour leur validité heuristique et leur dimension prescriptive 22.

\section{LES ORIENTATIONS THÉORIQUES ET MÉTHODOLOGIQUES DES ÉTUDES CONSACRÉES AUX ÉLITES EN POLOGNE. APPROCHE CRITIQUE DE L'HISTORIOGRAPHIE}

La place qu'occupent les élites dans la sociologie politique polonaise tranche avec le sort que les analystes étrangers réservent à cet objet. L'analyse des élites y est en effet soudainement devenue une spécialité 23 . On s'explique ce contraste

20. Les thèmes de recherche ainsi que les orientations théoriques dépendaient largement, sous le régime communiste, des financements offerts. De plus, la longue tradition d'engagement des sociologues dans l'espace public a ses limites : elle n'est pas allée jusqu'à la remise en cause du régime précédent. Elle a au contraire pu justifier des comportements loyaux à l'égard du pouvoir. La confusion entre une recherche orientée logiquement vers l'analyse des transformations socialistes, dans la période de l'édification du socialisme, et une « policy orientedscience », telle que l'appelle Jerzy J. Wiatr, à l'usage des gouvernants est alors soigneusement entretenue. Wiatr est même allé jusqu'à démontrer que " l'adhésion » des sociologues à la République populaire de Pologne trouve son origine dans l'unité de la recherche sociologique et du mouvement socialiste dès 1870 ! (WIATR, 1974).

21. Les rapports complexes entre la sociologie polonaise et le pouvoir ne sont pas sans évoquer la dimension normative de la science politique américaine (BLONDIAUX, 1997 ; SMITH, 1997).

22. Même si c'est le cas pour l'ensemble des objets de science politique, le cas des élites en Pologne est emblématique d'une distance très grande prise à l'égard de la norme de neutralité axiologique.

23. C'est la raison pour laquelle on ne s'intéressera ici qu'aux travaux entièrement consacrés aux élites. On citera à titre d'évocation les publications dans lesquelles les élites ne constituent pas l'enjeu central. On n'analysera pas la production scientifique récente consacrée aux élites de la période communiste, tels que les travaux consacrés aux élites d'après-guerre (CONNELLY, 1996 ; WOJCIK, 1989 ; PASZTOR \& JAROSZ, 1999), les études sur le personnel politique post-stalinien (NARKIEWICZ, 1990 ; WOJCIK, 1994), celles portant sur la période Gierekienne et postGierekienne (LAZARZ, 1997 ; LEWIS, 1989 ; WASILEWSKI, 1990). On n'évoquera pas non plus les recherches qui portent sur les élites de Solidarité (BIESENSKI, 1996). On laissera également de côté les analyses des élites par des disciplines périphériques, telles que la science économique (Blejer \& CoRICELl, 1995) et la psychologie (SKARZYNSKA, 1996). Enfin, on n'évoquera même pas l'essayisme ou le commentaire semi-sociologique (KURCZEWSKA \& KAMINSKI, 1992 ; PODGORECKI, 1991 et 1994). 
tant par la curiosité sociale des Polonais pour la composition du personnel politique national que par l'évolution des pratiques et des préoccupations de la sociologie polonaise. La recherche sur la classe dirigeante est menée principalement dans deux instituts de recherche de l'Académie polonaise des sciences 24 . Ses directeurs, deux anciens sociologues de la structure sociale, Jacek Wasilewski et Wlodzimierz Wesolowski, se partagent ainsi un quasi-monopole sur l'édition universitaire consacrée à la question 25 . Les analyses se distinguent par le type d'élite prise pour objet. Si l'on s'intéressera ici essentiellement à la classe politique, d'autres catégories dirigeantes sont étudiées, au premier rang desquelles les élites économiques 26 , ainsi que les élites culturelles. Les études consacrées à l'intelligentsia, et notamment leurs rapports au champ politique, sont pléthore en Pologne. Tout dépend bien sûr du cadre théorique de référence. Les comparaisons morphologiques de certaines élites sociales (Szelenyi, Treiman \& WnukLipinski, 1995) s'appuient sur une conception parétienne : l'élite reçoit une définition large, non réduite à sa fraction gouvernementale ; elle est composée des individus des classes supérieures des différents segments sociaux. Les frontières de l'élite politique elle-même ont évolué. Les chercheurs étudient dans un premier temps les parlementaires. Le premier ouvrage collectif paru sur les élites politiques polonaises est une analyse de la composition bio-sociale ainsi que des représentations des députés de l'Assemblée dite contractuelle 27. Les dirigeants des partis sont analysés dans un second temps (Grabowska \& Szawiel, 1993) 28, de même que les élites gouvernementales (Baylis, 1994). Si les députés restent le personnel politique le plus étudié 29 , les échantillons se diversifient progressi-

24. L'Instytut Studiow Politycznych Polskiej Akademii Nauk (ISP PAN) (Institut d'études politiques de l'Académie polonaise des sciences) est l'ancien Instytut Nauk Politycznych $i$ Badania Krajow Socjalistycznych (Institut d'études politiques et de recherches sur les pays socialistes). Jacek Wasilewski y dirige un laboratoire consacré exclusivement aux élites : Instytut Zaklad Studiow nad Elitami (Institut d'étude des élites) ; l'Instytut Filosofii $i$ Socjologii Polskiej Akademii Nauk (IFiS PAN) (Institut de philosophie et de sociologie de l'Académie polonaise des sciences) héberge le laboratoire de Wlodzimierz Wesolowski : Zakladzie Struktur Wladzy (La structure institutionnelle du pouvoir).

25. Les ouvrages principaux consacrés aux élites depuis 1992 sont des publications collectives: WASIlEWSKI \& WeSOlowSKI, 1992 ; PALECKI, 1992 ; GRABOWSKA \& SZAWIEL, 1993 ; WASILEWSKI, 1994a ; PANKoW \& WesoloWSKI, 1995 ; SZELENYI, TREIMAN \& WNUK-LiPINSKI, 1995 ; POST \& WESOLOWSKI, 1998 ; WASILEWSKI, 1999a.

26. De nombreuses études ont par exemple été consacrées aux nouveaux entrepreneurs économiques, d'autres à la mobilité sociale. L'une des interrogations sociologiques des premières années postcommunistes est de distinguer les perdants et les gagnants des changements socioéconomiques (MinK \& SZUREK, 1994C ; Borocz \& RonA-TAS, 1995).

27. Au terme de la Table ronde nationale qui réunit en 1989 les représentants du pouvoir et de l'opposition démocratique, il est décidé d'organiser des élections semi-libres. $35 \%$ des sièges de la Diète seraient disputés au pluralisme tandis que les $65 \%$ restants seraient réservés à des candidats des partis du pouvoir. Les $35 \%$ des sièges disputés démocratiquement ont tous été remportés par des candidats de Solidarité (WASILEWSKI \& WESOlowSKI, 1992).

28. Le second ouvrage dirigé par J. Wasilewski élargit l'échantillon et prend en compte les leaders partisans (WASILEWSKI, 1994a).

29. Ainsi les travaux menés autour de W. Wesolowski sont exclusivement consacrés aux parlementaires (PANKOW \& WesOlowski, 1995 ; Post \& Wesolowski, 1998). Lire également JACKIEWICZ, 1996. 
vement : les élites syndicales 30, religieuses 31, économiques (Drag, 1999) sont ensuite étudiées comme des segments de l'élite politique. Cet élargissement continu semble ainsi révéler une constante actualisation de la définition des élites. D'abord étroitement restreinte à ses frontières institutionnelles - le Parlement et les partis politiques sont alors considérés, comme le remarque Wasilewski, comme les institutions de base de la démocratie (Wasilewski, 1996) -, la définition s'étend peu à peu à des catégories moins stabilisées du jeu politique à mesure qu'est reconnue l'influence qu'elles exercent dans la vie politique et dans les processus de décision. Le faible intérêt porté aux élites administratives suscite dès lors de nombreuses interrogations 32 . Enfin, l'examen de la production éditoriale consacrée aux élites révèle une forte prédominance de l'intérêt pour les dirigeants nationaux au détriment des leaders locaux.

\subsection{LA CONSOLIDATION DÉMOCRATIQUE COMME HORIZON POLITIQUE ET PRÉSUPPOSÉ SOCIOLOGIQUE. UN USAGE AMBIGU DES RESSOURCES THÉORIQUES}

Dans sa présentation des orientations théoriques de l'analyse des élites politiques polonaises, Wasilewski indique que les « études qui s'appuient sur la théorie des élites » sont moins nombreuses que les approches descriptives ou les analyses générales du changement dans lesquelles les élites sont convoquées à titre secondaire (Wasilewski, 1996) 33. Il convient néanmoins d'explorer l'espace théorique dans lequel se déploient ces études. La diversité et l'usage des auteurs convoqués à l'appui des recherches empiriques renvoient l'image d'un syncrétisme théorique : les outils mobilisés le sont souvent à titre anecdotique, comme c'est parfois le cas de la théorie du capital de Bourdieu, utilisée pour rendre compte des mécanismes de reconversion des ressources de la nomenklatura communiste dans le nouveau régime. Le concept de «capital », décliné en capital social et capital politique notamment, fait en effet l'objet d'un usage métaphorique, par simple analogie avec le capital économique, sans jamais être référé à une analyse de la structure de distribution de ce capital dans le champ dont il est issu. Les œuvres citées en soutien aux hypothèses sont souvent insuffisamment discutées, à l'image du programme théorique de Burton et Higley (Burton \& Higley, 1989), qui bénéficie d'une grande notoriété parmi les chercheurs mais qui est rarement discuté par la sociologie locale. Enfin, certaines références prestigieuses, à l'image de Max Weber, dont la démarche typologique est très utilisée, semblent justifier tous les réductionnismes méthodologiques. En dehors de

30. Jaroslaw Pawlak compare par exemple les caractéristiques socio-démographiques d'une population composée d'élites partisanes, de responsables syndicaux, de leaders d'associations de la « société civile » et du monde économique et de « leaders d'opinion » (conseillers présidentiels et ministériels et hommes des médias), in PAWLAK, 1997.

31. Il s'agit plus de réflexions appuyées sur des sondages d'opinion que de véritables analyses des élites religieuses (MARIANSKI, 1992).

32. Elles sont toutefois intégrées dans la population étudiée dans WASILEWSKI, 1999.

33. On peut y lire la reconnaissance implicite de la faiblesse théorique de certains travaux. 
quelques travaux, la pluralité théorique apparente cache en réalité des intuitions et des présupposés communs.

\subsubsection{Une souche théorique commune}

Le premier présupposé théorique est sans doute la prégnance du contexte historique de changement et de formation d'un nouveau régime politique. Plus qu'un élément du cadre spatio-temporel, le processus de changement de régime est le point central, qui attire toutes les attentions. Quelles que soient les modalités d'analyse, l'objet étudié, les élites, est systématiquement rapporté au contexte global. Cette prégnance du référent politique, si elle ne peut être contestée, réduit néanmoins la variété des questionnements possibles. Elle ne permet pas d'envisager par exemple l'étude de phénomènes politiques spontanément associés à des configurations politiques stabilisées, tels que les processus de définition des modalités d'exercice du métier politique. Non que les conjonctures propres aux périodes de formation d'un régime politique ne puissent offrir des conditions favorables d'observation des pratiques politiques et des phénomènes d'institutionnalisation - nous pensons au contraire que si - mais elles induisent le risque d'élargir la focale d'analyse, de globaliser le regard du sociologue, de le rendre aveugle à des phénomènes et des processus plus étroits, plus enfouis dans la réalité sociale que les grandes tendances abondamment décrites ( «transition », " démocratisation », « mondialisation », etc.), et qui, constamment, menacent d'absorber tous les questionnements.

La seconde hypothèse théorique, partagée par de nombreux auteurs, est l'idée de l'autonomie des élites politiques dans les situations de changement de régime. Le credo d'une explication «par le haut » des changements politiques y trouve son origine. Cette hypothèse est bien résumée par Wesolowski, évoquant les premiers mois du changement de régime : «À cause de la faible articulation des structures de la société civile en Pologne, les élites politiques n'étaient pas soumises à des demandes sociales et des pressions précises. Elles opéraient, en un sens, dans un espace "indéterminé" de choix politiques » (Wesolowski, 1992, p. 78) 34. Outre qu'il permet de se démarquer des conceptions marxistes

34. L'auteur considère que la Table ronde polonaise de 1989 a révélé l'autonomie relative des élites : « En dépit du fait que ceux qui représentent les communistes et l'opposition reflètent cette profonde division sociale et politique, quand ils se sont assis à la table de négociation, ils ont bénéficié d'une autonomie complète vis-à-vis des grandes structures sociales et des organisations qu'ils prétendaient représenter. Le camp communiste n'avait ni mandat ni instructions de la part de la base du Parti pour entreprendre les discussions ou pour arriver à un objectif particulier (...) De même, les représentants de Solidarité n'avaient aucune instruction de la part de leur propre base sociale » (WESOLOWSKI, 1992, p. 80). Si la réalité de l'autonomie relative des élites est difficilement contestable, l'auteur ne la démontre pas à l'aide de preuves empiriques tangibles. Pour une approche différente de l'autonomie de l'action des élites pendant la Table ronde, se reporter à une application originale de la théorie des jeux (Colomer \& Pascual, 1994). 
des élites (la classe politique comme instrument de la classe dominante) et des analyses classiques (les élites articulent et représentent les intérêts sociaux), ce positionnement théorique contribue à légitimer l'objet. Il ouvre du même coup le champ du questionnement au problème du rôle joué par les élites dans le changement de régime.

\subsubsection{L'ombre tutélaire d'une sociologie américaine}

Les analyses de John Higley, Richard Gunther et Michael G. Burton jouent à cet égard un rôle essentiel (Burton \& Higley, 1989 ; Gunther \& Higley, 1992 ; Higley \& Pakulski, 1992 ; Higley, Pakulski \& Wesolowski, 1998a ; Higley \& Pakulski, 1999). Cette suite d'articles et d'ouvrages rédigés en binômes ou trios a en effet alimenté un schéma d'analyse des changements de régime établissant une relation entre les transformations qui affectent les élites et les transformations du régime. On ne pourrait comprendre les mécanismes de transition politique qu'en étudiant les changements internes aux élites nationales. À chaque type de régime correspondrait un type d'élites. Leur analyse serait par conséquent un observatoire du changement de régime. Ainsi, les mécanismes de transition démocratique se révèleraient-ils dans la constitution d'une « élite unifiée autour d'un consensus » équivalant aux élites pluralistes propres aux démocraties modernes 35. Une telle grille de lecture favorise bien entendu la construction de typologies : la Pologne bénéficierait, comme la Hongrie ou la République tchèque, de la formation d'une « élite consensuelle », tandis que leurs voisins bulgares et slovaques composeraient avec une «élite fragmentée », la Roumanie et l'Ukraine se contentant d'une « élite divisée » (Higley, Pakulski \& Wesolowski, 1998b). L'apport essentiel de cette perspective est qu'elle inverse les questionnements classiques : on ne s'intéresse plus aux causes, notamment politiques, qui déterminent la transformation des élites 36 : ce sont les élites ellesmêmes qui déterminent les transformations politiques. Outre qu'une telle démarche suscite un certain nombre de réserves 37 , son usage par les sociologues polonais pose problème. Même si le projet théorique des politistes américains est le produit d'une observation 38, il est utilisé en Pologne sous la forme d'un schéma abstrait de relations décontextualisées entre types d'élites et types de régimes. Ainsi, plutôt que de s'y référer au cours de l'observation, la démarche employée par certains auteurs est de poser le schéma en préalable à la recherche 39 . L'enjeu de celle-ci se réduit dès lors à vérifier la validité heuristique d'un modèle élaboré à partir de matériaux très différents (Wesolowski, 1992).

\footnotetext{
35. «Une élite nationale est unifiée autour d'un consensus quand ses membres partagent en gros un consensus tacite sur les règles et les codes du comportement politique, allant jusqu'à l'euphémisation de l' "esprit de parti" et participant avec plus ou moins de compréhension à une structure d'interactions intégrée qui leur fournit un accès relativement confiant et efficace l'un à l'autre et à ceux qui prennent les décisions » (BURTON \& HigLeY, 1989, p. 19). Les auteurs distinguent ce type d'élites des élites « unifiées autour de l'idéologie» ou « élites totalitaires », ainsi que des élites « divisées » ou « désunies », qui ne s'accordent pas sur les règles du jeu politique.
} 
À la fois schéma descriptif et théorie deshistoricisée et universalisable, le modèle suscite une lecture normative : « La typologie simplifiée des élites politiques inclue un élément évaluatif clair : le type désirable est celui d'une élite consensuellement unie (pluraliste), dans la mesure où ce type seul est lié à un système démocratique stable » (Wasilewski, 1992, p. 44) 40. L'objet de la recherche n'est même plus, par conséquent, d'éprouver la théorie dans le cas polonais. Il est d'adopter une posture davantage politique que sociologique : «Si les élites pluralistes (unies autour du consensus) sont le type le plus souhaitable étant donné ses liens avec les démocraties stables, alors le problème clé est : comment de telles élites se forment-elles ? Est-il possible, et comment, de stimuler leur émergence dans les anciens pays communistes? » (Wasilewski, 1992, p. 45). Cette confusion entretenue entre les objectifs sociologiques et politiques de la recherche sur les élites ne peut bien entendu être généralisée à tous les travaux répertoriés. Elle ne manque pas cependant de faire écho aux principales critiques adressées aux postures «transitologiques» (Michel, 1994 ; Milacic, 1996 ; Santiso, 1996 ; Hermet, 2000). L'emploi de la notion de transition, pour désigner un processus politique inachevé, pose en effet de graves problèmes méthodolo-

36. Se reporter à la fresque des théories de la transformation des élites de Robert Putnam (PUTNAM, 1976).

37. Notamment en ce qui concerne la méthode utilisée, le degré de montée en généralité et l'adaptabilité du modèle dans les démocraties émergentes en Europe centrale. L'essentiel du raisonnement et la logique de la preuve sont en effet très discutables.

38. Ils ont en effet étudié et comparé les relations entre régimes et élites dans des situations socio-historiques très différentes, « dans les États-nations occidentaux après 1500 ».

39. Les auteurs de cette théorie considèrent que « Le rôle central des élites dans les sociétés communistes et postcommunistes montre [...] la valeur du paradigme élitaire pour guider la recherche sociologique et politologique. Le paradigme est source de plus grandes promesses intellectuelles que les paradigmes concurrents orientés sur la classe ou les phénomènes de masse » (Higley \& PAKULSKI, 1999, p. 2). Mais, « utiliser le concept d'élite n'est pas la même chose qu'adopter le paradigme des élites». Et ces auteurs de définir ce qu'ils appellent « the elite paradigm », dont ils déterminent cinq caractéristiques principales : «L'universalité des élites », "Les élites sont les principaux facteurs des ordres politiques », " Les structures élitaires, les responsabilités des élites et leurs traits de comportements créent les distinctions de base entre tous les systèmes et régimes politiques », « Les élites (...) sont des groupes sociaux et leur cohésion est un élément de pouvoir sur les non-élites », "Les élites produisent des effets socio-culturels considérables ». Plus qu'une construction théorique à des fins heuristiques, le «paradigme des élites » apparaît comme une forme de charte, à laquelle on adhère ou non. On peut penser qu'elle suppose davantage de croyance et de confiance que d'application sociologique. Le paradigme élitaire suppose d'en partager les constituants, les promesses (et les échecs ?). L'acte de foi de Higley et Pakulski pour un paradigme est une pratique semble-t-il assez courante, comme l'illustre par exemple la défense par Eva EtzioniHalevy d'une perspective théorique « classe-élite » (ETZIONI-HALEVY, 1998).

40. Il faut reconnaître ici que les auteurs de cette théorie eux-mêmes encouragent un tel usage de leurs travaux : «Les démocraties stables n'émergent pas simplement de l'écriture de constitutions, de la tenue d'élections, de l'expansion des droits de l'homme, de l'accélération de la croissance économique ou de l'extermination des insurrections gauchistes. L'étape essentielle est l'unification consensuelle d'élites auparavant désunies (...) Ce fait suggère fortement aux pays occidentaux qu'ils peuvent faire un peu pour promouvoir des démocraties stables là où aujourd'hui elles n'existent pas » (BURTON \& Higley, 1989, p. 29). 
giques. L'un d'entre eux concerne la dimension prédictive et normative de certains questionnements, aboutissant à analyser les objets politiques et sociaux par défaut, en mettant en évidence ce qu'ils ne sont pas encore mais qu'ils seront bientôt. Ce sont plus des « manques », des « difficultés », des « retards » de la démocratisation ou des excès (de la fragmentation partisane avant 1993 par exemple), mesurés à l'aune d'une représentation impensée de la démocratie idéale 41 , que l'émergence et la formation des institutions du nouveau régime qui suscitent l'attention.

\subsection{LES USAGES MULTIPLES D'UNE SOCIOLOGIE QUANTITATIVE. ENSEI- GNEMENTS ET LIMITES DES ANALYSES MORPHOLOGIQUES.}

Le recours à l'analyse morphologique est une des caractéristiques des travaux consacrés aux élites en Pologne. Un nombre important d'analyses sociographiques des personnels politiques nationaux a été publié. Mais ces classifications répondent à des objectifs théoriques différents. Le plus immédiat est la description détaillée d'un type de personnel politique (Nalewajko, 1992 ; Grabowska \& Szawiel, 1993 ; Wasilewski, 1995a ; Wasilewski, 1999b). L'apport d'une telle classification n'est pas uniquement descriptif. Cet outil permet également de révéler l'existence d'indicateurs de rôles politiques dont procède la composition des élites. L'analyse sociographique est, dans cette conception, la pièce centrale d'une analyse des règles de recrutement non institutionnelles des élites politiques. La richesse de ces enseignements dépend bien entendu des critères de classement utilisés. Le sexe, l'âge, le niveau de formation, l'origine sociale sont les caractéristiques sociales les plus fréquemment enregistrées. L'approche quantitative favorise également la comparaison des types de personnel politique (Pawlak, 1997) ainsi que l'évolution de la composition d'une élite dans le temps (Jackiewicz, 1994). L'emploi, enfin, de la méthode agrégée favorise la comparaison des résultats des différentes études, dès lors bien sûr que tant la structure des échantillons que la structure des taxinomies sont comparables.

\subsubsection{Morphologie du personnel politique}

L'ensemble des études sociographiques révèle ainsi des tendances communes, que résument les analyses de Jacek Wasilewski. Prenant appui sur une partie des résultats des enquêtes menées par une équipe internationale en 1993 (Szelenyi, Wnuk-Lipinski \& Treiman, 1995 ; Theory and Society, 1995), ce dernier cherche à identifier ce que sont les nouvelles règles de recrutement du personnel politique, à partir de données recueillies sur un échantillon de 282 personnes constitué de parlementaires, de membres de cabinets ministériels, de haut fonctionnaires des administrations centrales et régionales (Wasilewski, 1995a).

41. Comme l'indique très justement Jacques Derrida, «Cela suppose que nous ayons de la démocratie un modèle rigoureux, une expérience assurée, un concept arrêté, at home, chez nous en Occident » (DERRIDA, 1995, p. 35). 
L'auteur commence par rappeler les conditions politiques dans lesquelles l'élite appréhendée s'est constituée : le morcellement du syndicat Solidarité sous la forme de plusieurs partis politiques de droite, l'intégration dans la vie politique de l'ancien Parti ouvrier, sous la forme d'une social-démocratie rénovée, l'institutionnalisation sur la scène nationale de partis politiques de droite non issus de Solidarité et la réintégration des partis satellites de l'ancien Parti communiste dans la compétition politique. Convaincu de la difficulté à représenter l'élite selon l'ancien clivage opposant les communistes aux membres du camp de Solidarité, il convient de l'examiner en vertu d'autres critères que l'étiquette portée lors de l'élection ou l'appartenance à tel groupe parlementaire. Il décide d'étudier les membres de son échantillon en fonction de leur parcours social et politique, avant d'identifier les facteurs qui agissent sur les attitudes, par exemple religieuses, des personnes interrogées. Wasilewski ne néglige pas d'identifier les déterminants sociaux (sexe, âge, formation, profession du père, profession des membres de l'échantillon) ainsi que les caractéristiques politiques (affiliation dans le passé au Parti communiste, affiliation du père au Parti, affiliation à un parti satellite, appartenance à Solidarité) des élites, avant de croiser les préférences politiques en 1993 avec l'origine politique (le camp de Solidarité, le camp communiste ou aucun d'entre eux) dans les deux sens de la relation. Il croise enfin les origines politiques (toujours définies de manière manichéenne), puis la préférence politique en 1993 avec le degré de la pratique religieuse à la même date.

L'élite nationale polonaise est en majorité masculine $(87,9 \%)$, jeune $(64,9 \%$ ont moins de 50 ans), hautement diplômée (93,3\% sont diplômés du supérieur) et une faible partie du groupe appartenait à la nomenklatura en $1988(20,9 \%)$. Par ailleurs, la composition sociale de l'élite indique l'exclusion de la classe ouvrière ainsi que des agriculteurs des catégories dirigeantes au profit des chefs d'entreprise et professionnels indépendants. Enfin, si une majorité d'entre eux affirme ne jamais avoir appartenu au POUP $(69,5 \%)$, ou l'avoir quitté avant $1988(7,8 \%)$, moins de la moitié des membres du groupe a appartenu à Solidarité $(42 \%)$. Ce dernier résultat invalide la persistance de l'ancien clivage « eux-nous » dans la composition des élites politiques. Celles-ci seraient traversées de clivages plus complexes, marquée par l'euphémisation des oppositions, en raison d'un recrutement social peu hétérogène : "Le camp actuel de "Solidarité" n'est qu'une petite partie de l'ancien mouvement de masse comprenant principalement des leaders anti-communistes radicaux et le courant de syndicalistes dévoués au sein de Solidarité. Le camp communiste s'est aussi dispersé, même si le fractionnement est clairement moindre, et le noyau principal de ce camp se trouve à présent soit parmi la gauche soit parmi l'aile gauche de l'Union de la Liberté »42. L'élite politique ne se composerait donc pas des

42. L'Union de la liberté est un parti généralement situé au centre de l'échiquier politique (WASILEWSKI, 1995a, p. 128). 
anciens membres les plus actifs des structures de l'ancien régime ni des opposants au régime les plus investis. De plus, les membres de la nouvelle élite ne seraient membres, pour la plupart $(72,3 \%)$, d'aucun parti politique. L'auteur croise ensuite préférences politiques (pour une famille politique) et origine politique (Solidarité, le Parti communiste, autre). Les origines politiques influenceraient fortement les préférences politiques présentes sans les déterminer totalement. $35 \%$ d'anciens communistes rejoignent en effet les rangs libéraux ou conservateurs. De même, si le degré de pratique religieuse varie nettement en fonction de l'origine politique et des préférences politiques, ces facteurs ne le déterminent pas nécessairement, comme en témoigne, par exemple, la forte pratique religieuse $(36,5 \%$ une fois par mois, $19 \%$ une fois par semaine) des anciens communistes.

La principale critique adressée à cette étude réside dans le fait que les préférences politiques en 1993 aient été uniquement croisées avec des variables politiques et religieuses et non avec les attributs sociaux des personnes interrogées, ce qui aurait sans doute montré l'existence de disparités sociales et professionnelles entre les membres d'une élite diversifiée et politiquement structurée. Elle révèle également les limites d'une approche uniquement quantitative. Elle ne dit rien en effet de l'influence pratique qu'exerce la détention de telle ou telle ressource sociale ou politique sur l'accès à l'élite.

\subsubsection{Carences et prolongements des analyses sociologiques}

L'historiographie des élites françaises montre que la sociographie des élites politiques peut constituer un instrument redoutable au service d'une critique sociologiquement argumentée du fonctionnement des institutions représentatives (Sawicki, 1999). Les sociologues polonais semblent au contraire n'avoir aucun goût pour la mise en évidence des apories de la démocratie 43 . La démonstration de la non-représentativité sociale des gouvernants est peu indiquée, il est vrai, dans une société où un certain nombre de groupes sociaux ainsi que les élites elles-mêmes valorisent les critères méritocratiques de mobilité sociale au détriment des préoccupations égalitaristes. Elle l'est d'autant moins pour une sociologie si préoccupée de la légitimation des institutions démocratiques. L'absence frappante de tels questionnements n'est pas enfin sans évoquer la disqualification des raisonnements néo-marxistes. Même s'il se limite à l'inégalité la plus criante, celle des sexes, un courant d'analyse semble toutefois se constituer autour de la critique de la fiction d'une représentation qui marginalise les femmes dans la vie politique (Post, 1997 ; Siemienska, 2000). Une seconde utilisation des analyses sociographiques a été richement éprouvée concernant les élites polonaises. Il s'agit de l'étude des trajectoires sociales. S'appuyant sur une comparaison de la composition des élites à deux moments différents, la

43. L'étude des élites est pourtant un élément essentiel des réflexions portant sur les rapports entre démocratie et égalité (BOTTOMORE, 1964). 
démarche méthodologique est mise au service de la démonstration d'hypothèses théoriques clairement exposées. Menées notamment par des spécialistes de la stratification et de la mobilité sociales, ces recherches ont exploré les hypothèses de reproduction et de circulation des élites sociales (politiques, mais aussi économiques et culturelles) en Pologne, Hongrie et Russie (Theory and Society, 1995) 44. Deux questions structurent cette recherche : que sont devenues les anciennes élites communistes ? D'où proviennent les élites actuelles ? L'objectif est de vérifier empiriquement les théories opposées de la reproduction des anciennes catégories dirigeantes 45 et de leur remplacement (Szelenyi \& Szelenyi, 1995).

\subsubsection{Reproduction et circulation}

Les recherches ont montré la coexistence des phénomènes de reproduction et de circulation. Ainsi, l'on assisterait à une forte reproduction de la nomenklatura puisque 38,2 \% des nomenklaturistes de 1988 feraient encore partie de l'élite en 1993 46. Un tiers de la nomenklatura serait à la retraite, un sixième environ d'entre elle aurait connu un déplacement régressif dans la hiérarchie sociale. Par contraste, $21,4 \%$ des membres de l'élite étudiée en 1993 sont entièrement nouveaux et $40,7 \%$ de cette élite est issue de la nomenklatura. Ces résultats doivent cependant être différenciés par type d'élite. Ainsi, la reproduction est plus importante pour l'ancienne nomenklatura économique (elle se maintiendrait à $70 \%$ ) que pour l'ancienne nomenklatura culturelle $(61 \%)$ et surtout politique $(27,5 \%)$. L'élite politique en 1993 serait de surcroît la fraction de l'élite polonaise la plus ouverte puisqu'elle est issue à $43 \%$ de catégories sociales extérieures à l'élite précédente. La relative importance de la circulation s'expliquerait d'abord par l'auto-exclusion des élites communistes qui craignent les effets de l'exposition électorale des candidats lors des scrutins. On y verrait aussi l'effet de la facilité à remplacer les détenteurs de positions politiques dans la mesure où elles ne requièrent pas de compétences spécifiques. Les auteurs y décèleraient également des phénomènes de récompense des membres de l'opposition démocratique (Fodor, Wnuk-Lipinski \& Yershova, 1995) 47. Les auteurs concluent de ces résultats et des comparaisons effectuées entre la Pologne, la Hongrie et la Russie que la composition des élites est marquée par la prégnance du passé communiste : «Même en politique, la révolution était plus apparente que réelle » (ibid., p. 634).

44. Les auteurs s'appuient sur... 40000 entretiens menés dans six pays (Bulgarie, République tchèque, Pologne, Russie, Hongrie, Slovaquie). Seuls des résultats partiels et ne concernant que trois pays ont été publiés ; lire aussi WASILEWSKI, 1994b et WASILEWSKI, 1995b.

45. La conception dominante de la reproduction des anciennes élites est par exemple défendue par J. Staniszkis (STANISZKIS, 1991).

46. Cette proportion est de $57 \%$ si on élargit la définition de la nomenklatura à ce que les auteurs appellent les « supervisors ».

47. On ne voit pas très bien, cependant, comment ce phénomène de récompense peut s'imposer dans la réalité sociale sans s'appuyer sur des mécanismes incitatifs dont on peut raisonnablement penser qu'ils en sont l'explication. 
Deux sociologues participant à l'étude explorent plus précisément ces hypothèses. Mais ils étudient uniquement les phénomènes de reproduction, sur la base de l'origine des nouvelles élites et non du devenir de l'ancienne (Wasilewski \& Wnuk-Lipinski, 1995). Ils distinguent la « reproduction intergénérationnelle » (reproduction de la nomenklatura par les rejetons de la nomenklatura) et la « reproduction intragénérationnelle » (lorsque les détenteurs des nouvelles positions élitaires sont d'anciennes élites elles-mêmes). C'est bien entendu la reproduction intragénérationelle qui est la plus importante. Elle serait plus fréquente dans les secteurs de l'économie et de la culture que dans le secteur politique. Les auteurs distinguent alors trois modalités de la reproduction : la « reproduction simple », la « reproduction par conversion » (lorsque d'anciens membres de la nomenklatura maintiennent leur statut social mais appartiennent maintenant à une autre fraction des élites) et la « reproduction verticale » (il s'agit des individus qui n'appartenaient pas encore formellement à la nomenklatura sous le communisme mais qui y étaient destinés). Les auteurs découvrent l'importance de la reproduction simple dans l'économie et la culture où semblent se maintenir des critères d'accès basés sur le mérite ; la reproduction par conversion se manifesterait par le « transfert d'un poste de directeur nomenklaturiste à la position de propriétaire, d'actionnaire principal ou de chef de la direction exécutive d'une entreprise privée » (ibid., p. 689) : on assisterait ainsi à la conversion réussie du «capital politique » en «capital économique ». L'étude apporte d'incontestables enseignements mais souffre de nombreuses limites. Outre la focalisation de l'analyse sur les formes de reproduction uniquement, celles-ci tiennent également à la composition des échantillons : les frontières entre les catégories économiques, culturelles et politiques de l'élite ne sont pas clairement exposées. Par ailleurs, l'indifférenciation de l'élite politique, présentée comme étant artificiellement homogène, n'indique rien des trajectoires les plus valorisées entre une position de nomenklaturiste et la détention d'un type particulier de mandat.

\subsubsection{Conversion(s)}

Les travaux de Georges Mink et Jean-Charles Szurek explorent la même veine théorique (Mink, 1993 ; Mink \& Szurek, 1992a, 1992b, 1993, 1994a, 1994b, 1995, 1998, 1999a). Ils enrichissent considérablement les analyses quantitatives précédentes en ce qu'ils analysent les stratégies de reconversion des nomenklaturistes dans l'économie capitaliste à partir des récits qu'en font les acteurs. Les auteurs cherchent également à analyser les effets de ces phénomènes sur les modes de définition et de rationalisation des nouvelles identités publiques des personnes interrogées. D’abord consacrées aux élites économiques, les analyses de Mink et Szurek ont été récemment élargies à la reconversion de certaines élites politiques communistes dans le monde postcommuniste (Mink \& Szurek, 1999b), mais l'on peut regretter que les auteurs aient omis de définir sociologiquement le terme de conversion, notion attrape-tout qui désigne autant le « processus historique " de "conversion des sociétés de type soviétique vers l'économie de marché, du communisme vers le capitalisme » (Mink \& Szurek, 1999b, p. 14), la conversion des identités publiques des partis et des élites com- 
munistes en sociaux-démocrates (Mink \& Szurek, 1999b, chapitre 1) que les mécanismes de conversion de certains nomenklaturistes en entrepreneurs capitalistes (Mink \& Szurek, 1998 ; Mink \& Szurek, 1999b, chapitre 2). S'il s'agit d'un transfert de ressources d'un champ social à un autre, la conversion est d'abord un comportement, qu'il faudrait pouvoir décrire et mesurer.

Il est cependant incontestable que leurs travaux ouvrent le questionnement. Il faudrait par exemple étudier la manière dont les anciens nomenklaturistes se comportent dans le nouveau contexte politique : comment ces entrepreneurs politiques font-ils usage des ressources accumulées sous le régime précédent, tant dans les stratégies déployées pour se maintenir dans l'espace politique (appui sur des réseaux rémanents, expérience politique) que dans la reconstruction de leur identité politique (formes de présentation de soi, valorisation de certaines caractéristiques) ? 48. Les ressources sur lesquelles ils s'appuient sont-elles les mêmes que sous le socialisme d'État ? Parviennent-ils réellement à se maintenir longtemps dans l'espace politique et à quel prix ? Puisqu'ils transfèrent - outre leurs ressources - des compétences, des savoir-faire et des aptitudes à exercer un « métier politique », dans quelle mesure ce faisant contribuent-ils à la définition des activités politiques aujourd'hui, à la délimitation des frontières entre activités administratives, syndicales, économiques et politiques ? Il serait également judicieux de prolonger la problématique de la conversion en observant les comportements politiques des nomenklaturistes reconvertis dans l'économie et, plus largement, des nouvelles élites économiques. Les entrepreneurs économiques font-ils en nombre des « investissements politiques », en se présentant par exemple aux scrutins électoraux, à l'instar de Stanislaw Tyminski qui était parvenu au second tour de l'élection présidentielle de 1990 ou de Kazimierz Piotrowicz, industriel candidat à l'élection présidentielle suivante ? Comment le cas échéant s'appuient-ils sur des ressources accumulées au cours de leurs activités économiques ?

Pour résumer, ces diverses analyses sont très intéressantes en ce qu'elles visent à reconstituer et comparer des trajectoires sociales et, ce faisant, à rendre compte de la constitution de nouveaux groupes sociaux et du devenir d'anciennes catégories sociales. L'hypothèse très significative de la conversion des ressources des acteurs reçoit par conséquent une confirmation empirique 49 . On peut se demander néanmoins si la porte ouverte par ces recherches doit maintenant être refermée, tel que le préconise Wlodzimierz Wesolowski (Wesolowski, 1999).

\footnotetext{
48. G. Mink et J.-C. Szurek évoquent par exemple les stratégies de légitimation de certaines élites postcommunistes : revendication d'une compétence politique, évocation des « droits d'auteur " de la « révolution », ces élites ayant participé comme en Pologne aux tables rondes de 1989, etc. (MinK \& SZUREK, 1999b).

49. L'analyse des parcours politiques à travers l'hypothèse de la reconversion d'un type de ressources ou de capital emprunte aux travaux de Pierre Bourdieu. Elle n'a pas donné lieu à une analyse systématique. Voir toutefois la mise en évidence, dans la situation russe, d'un type de capital convertible, le capital bureaucratique (CHMATKo \& SAINT-MARTIN, 1997).
} 
Celui-ci considère en effet que la notion de conversion est source de confusions. Dans l'acception de Szelenyi et Treiman (Theory and Society, 1995) - et dans celle de Mink et Szurek -, la conversion est une modalité de reproduction des élites. La notion contribuerait ainsi à rendre compte d'une partie des trajectoires des anciennes élites à côté de la reproduction simple (maintien dans une même position). Wesolowski propose de rendre à la notion de reproduction un sens qu'il juge plus pertinent, celui de la sociologie de la mobilité sociale. La reproduction désignerait uniquement la mobilité intergénérationnelle, distincte des phénomènes de rétention (et non reproduction simple) et de transfert (et non reproduction par conversion).

\subsubsection{Continuité des critères de sélection des élites}

La comparaison de la composition de l'ancienne élite et de l'élite actuelle suscite toutefois d'autres usages. Certains chercheurs s'appuient par exemple sur une comparaison des caractéristiques sociales des élites communistes et des élites postcommunistes pour démontrer les évolutions qui affectent la composition des élites en fonction de certains critères de classification (Eyal \& Townsley, 1995 et, dans une perspective proche, Baylis, 1994). L'enjeu est par exemple de mettre en évidence la continuité des critères de recrutement politique sous le communisme et après le changement de régime. Ces auteurs considèrent que l'étude des trajectoires des individus ne permet pas de comprendre ce qui se joue dans la reproduction. Celle-ci ne peut être saisie que dans l'analyse des phénomènes de stabilisation des caractéristiques sociales des élites. Dès lors, il suffit de démontrer que l'ancienne élite formait une " classe supérieure " pour conclure, à l'appui d'une mise en évidence de la continuité des critères de représentation des deux élites, que les élites actuelles forment également une classe supérieure : « Se demander si les élites communistes se sont "reproduites" ou ont "circulé" n'est pas suffisant. Si une classe supérieure existait, et dans quelle mesure, forme le contexte de classe des changements de personnel : beaucoup de circulation au niveau individuel, par exemple, ne nous apprendra sans doute rien de la reproduction des privilèges et des avantages institutionnalisés durant la période communiste via la classe supérieure. La reproduction au niveau individuel, d'un autre côté, risque d'indiquer précisément l'opposé ; qu'une classe supérieure ne s'est pas formée et que par conséquent les membres de la nomenklatura n'étaient pas en mesure de profiter de ces mécanismes institutionnalisés durant la transition postcommuniste » (Eyal \& Townsley, 1995, p. 746).

L'attachement aux critères de recrutement plus qu'aux individus eux-mêmes élargit l'espace problématique sur les élites. Il permet notamment d'analyser les phénomènes de continuité de certaines règles "pragmatiques" du jeu politique. En mettant en évidence l'existence de certains indicateurs sociaux et politiques de rôles politiques et leur continuité au travers du changement de régime, il renseigne également sur les propriétés sociales et politiques qui sont valorisées dans la compétition politique. Mais les apports de cette méthode sont limités. Elle suppose d'abord que toutes les données soient comparables à travers le temps. 
Comparer la composition des élites avant et après le changement politique n'a de sens que si l'on n'omet pas d'insister sur le fait que les rôles politiques changent dans le même temps : la place des élites dans les dynamiques sociales, les rôles prescrits par les différents postes politiques se transforment. Comme l'explique Robert Putnam, « la prudence méthodologique est de mise quand on étudie la transformation des élites : les changements dans les processus politiques peuvent altérer la signification de rôles institutionnels définis » (Putnam, 1976, p. 166). De plus, cette méthode ne fait que suggérer l'existence des caractéristiques qui habiliteraient des individus à s'engager dans la compétition politique.

Ce type d'approche des personnels politiques n'est que la face quantitative d'une analyse qui doit s'appuyer sur une variété méthodologique plus grande : il faudrait en effet différencier les types de personnel politique en fonction du mandat exercé afin de rendre compte du différentiel de degré d'ouverture de certaines institutions à certaines catégories sociales. On gagnerait également à étudier en actes, par l'observation des pratiques politiques notamment, les mécanismes de valorisation de certaines ressources politiques. Il faudrait aussi reconstituer les processus par lesquels s'inventent ces rôles politiques, comment ils sont habités en fonction des propriétés sociales et des ressources politiques que l'on détient et de la distance entre les caractéristiques détenues et les propriétés reconnues comme légitimes. De façon générale, si les analyses morphologiques sont un apport incontestable à toute recherche sur les élites, il est toutefois recommandé de bien prendre conscience de leurs limites et rappeler que ce type d'approche est sujet à caution dans la mesure où il met rarement en question tant la pertinence des catégories de classification utilisées dans la démonstration que le travail social d'imposition de ces catégories.

\subsection{DE L'ANALYSE DES REPRÉSENTATIONS AU MÉTIER POLITIQUE. LES PROMESSES D'UNE APPROCHE NÉO-WÉBERIENNE.}

La sociologie des élites polonaises n'est pas seulement sociographique. Elle comprend également une série de travaux consacrés aux représentations des élites. La construction de typologies descriptives, associées par les auteurs à une démarche wéberienne, est à cet égard une constante de la production sociologique. On distingue notamment l'analyse des représentations des élites concernant un certain nombre d'enjeux sociaux, politiques et économiques. L'objectif théorique qui sous-tend ces études est, dans certains cas, de vérifier le degré de formation de « l'élite consensuelle » définie par Higley et Burton et le degré de « consolidation » des élites politiques. La seconde série d'interrogations concerne le métier politique. Ce champ de recherche se compose de l'étude des représentations que les élites ont du métier politique ainsi que de l'observation des pratiques politiques. Si l'enjeu théorique sous-jacent de certaines d'entre elles est également de vérifier l'existence d'une élite pluraliste unifiée, cet ensemble de recherches comprend toutefois une variété d'études dénuées de toute dimension prédictive ou prescriptive. Il est commode de les réunir par souci didactique en ce qu'elles peuvent être associées, sans que leurs auteurs s'y rattachent toujours explicitement, à une approche néo-wéberienne. 


\subsubsection{Valeurs et représentations des élites}

L'étude des représentations des élites est une préoccupation sociologique dès la première recherche collective consacrée aux députés de l'Assemblée contractuelle (Wasilewski \& Wesolowski, 1992). L'analyse des opinions des parlementaires est mobilisée au service de la vérification de l'hypothèse selon laquelle on assisterait à la formation d'une « élite consensuelle »: «Le problème de l'espace du consensus qui devrait servir de base à la formation d'une élite pluraliste, bien entendu, va au-delà des processus de formation de groupe. Il se rapporte d'abord à l'accord sur les valeurs fondamentales, incluant des valeurs politiques fondamentales. Est-ce qu'un tel accord s'est manifesté dans le cas des députés de l'Assemblée contractuelle ? »(Wasilewski, 1992, p. 50). S'appuyant sur le contenu d'entretiens effectués avec 35 députés, Wasilewski rend compte de l'existence d'un consensus très général sur la libéralisation et la démocratisation. 33 députés sur 35 considèrent qu'un accord existe sur de nombreuses questions fondamentales. Cependant, si le consensus est réel dans le domaine économique (encore que l'étendue et les voies de la privatisation et la politique agricole suscitent de profonds désaccords), certains enjeux politiques (et parmi eux, les rapports au passé communiste, la légalisation de l'avortement ou le rôle de l'Eglise dans la vie politique) divisent les députés. On peut se demander toutefois s'ils sont de nature à contrarier la formation d'une " élite consensuelle », dans la mesure où ils ne remettent pas en cause l'accord fondamental sur les règles du jeu politique (telle que l'acceptation du dialogue et du débat). Wasilewski conclut néanmoins à la division de l'élite qu'il appréhende cependant comme une étape sur le chemin de la formation d'un consensus 50.

C'est à l'étude de cette histoire que Wasilewski consacre ses publications postérieures. Chacune d'entre elles consacre une étape nouvelle de «l'apparition », de la «formation », puis de la « consolidation» de l'élite consensuelle. Ainsi, lorsque l'équipe de Wasilewski se penche sur les députés de la première législature (1991-1993), le processus de consolidation est encore dans sa « phase élémentaire » (Wasilewski, 1994a). L'analyse des « orientations » et des « valeurs » des élites que publie Wasilewski en 1997 manifesterait une (encore) « peu profonde consolidation de la démocratie polonaise » (Wasilewski, 1997b ; voir aussi Wasilewski, 1998). Le consensus entre les leaders polonais serait avant tout défini en négatif : ils s'accordent pour rejeter toute alternative non démocratique mais continueraient de s'opposer sur des enjeux déterminants. Néanmoins, « tous les éléments nécessaires à la stabilisation du système sont en place (...) la démocratie est l'unique jeu possible en Pologne ».

50. « Le cas de la Pologne semble confirmer la proposition avancée par Burton et Higley selon laquelle, dans la plupart des cas, le chemin vers une élite pluraliste passe par une élite divisée. Les processus que nous avons observés dans l'Assemblée semi-contractuelle et dans le système politique entier depuis 1990 n'étaient pas seulement des processus de construction d'une élite pluraliste. Ils signifiaient au contraire la désintégration d'un consensus politique apparent » (WASILEWSKI, 1992, p. 57). 
Tous ne partagent pas cependant le déterminisme des positions théoriques de Wasilewski. Miroslawa Grabowska et Tadeusz Szawiel par exemple se contentent d'analyser les opinions de l'ensemble des délégués aux premiers congrès politiques de certains partis. Dans un contexte de forte carence programmatique, les attitudes individuelles ont le statut d'indicateur des orientations politiques des partis (Grabowska \& Szawiel, 1993) 51. L'ouvrage que dirigent Irena Pankow et Wlodzimierz Wesolowski, consacré à l'étude du contenu de vingt-neuf entretiens menés avec des députés, se distingue des schémas de Wasilewski : plus modestes, les auteurs souhaitent rendre compte du « monde des élites politiques » (Pankow \& Wesolowski, 1995) 52. On retrouve néanmoins les mêmes axes de recherche. L'un des objectifs du livre est en effet de dévoiler les similitudes et les différences idéologiques et programmatiques des élites concernant les enjeux de politique intérieure (affaires sociales, "situation matérielle de la population ", intégration politique et commerciale dans l'Europe). Les députés décrivent ainsi leur vision de la transformation de l'économie (Stobinska, 1995), de l'intégration européenne (Skotnicka-Illasiewicz, 1995) ou évoquent la représentation qu'ils se font des facteurs de division et de consensus dans la société (Gortat, 1995). Il n'est pas rare que les opinions des élites soient comparées avec celles de la société, sur la base des sondages effectués par le Centre de recherches sur l'opinion sociale (CBOS). Ireneusz Bialecki et Bogdan W. Mach analysent par exemple les convergences et les divergences des conceptions politiques et socio-économiques des parlementaires élus en 1989 (Bialecki \& Mach, 1992b). La comparaison des résultats d'un sondage représentatif de la population (915 personnes) avec ceux d'un questionnaire adressé aux députés (263 réponses) montre un décalage entre la définition des priorités par la société et celles que défend l'élite au pouvoir. Les personnes interrogées (« la société ») attendent notamment des élites qu'elles luttent efficacement contre le chômage et réduisent les coûts sociaux entraînés par les réformes de libéralisation tandis que les priorités des députés de Solidarité sont notamment la continuation des privatisations. Les députés dits contractuels, présentés par le Parti communiste ou ses alliés, insistent quant à eux sur l'augmentation de la production industrielle. La comparaison met l'accent sur un paradoxe : « Les orientations sociales et économiques des députés de Solidarité - élus démocratiquement comme représentants de la société - différaient plus de celles de la société dans son ensemble que les orientations des députés qui ne disposaient pas de mandats

51. Voir aussi l'étude des opinions des leaders partisans polonais concernant «l'image des Polonais, la conception de la nation, la représentation du passé national " (KURCZEWSKA, 1996).

52. Comme J. Wasilewski dans le travail publié sous sa direction en 1994 , les auteurs de Swiat elity politycznej présentent cet ouvrage comme la continuité du livre sur les députés de l'Assemblée contractuelle. L'unicité des matériaux incite à relativiser l'apport d'une telle étude, ainsi que la méthode utilisée pour constituer l'échantillon. Les auteurs ont en effet conduit des entretiens avec les 21 députés sélectionnés par le journal Gazeta Wyborcza le 17 janvier 1993 dans son enquête sur les « meilleurs » députés. Ils ont ensuite demandé aux premiers députés rencontrés de leur indiquer « quelques bons collègues » pour étoffer l'échantillon. 
issus d'élections démocratiques. Les députés de Solidarité étaient en particulier les plus prolibéraux et les plus antisocialistes, les membres de la société étaient les plus antilibéraux et les plus prosocialistes, alors que les opinions des députés contractuels se situaient quelque part entre les deux » (Bialecki \& Mach, 1992b, p. 183).

Outre qu'elle confirme les désaccords parmi les membres de l'élite observés par Wasilewski (Wasilewski, 1992), cette étude révèle la diversité des formes prises par les premières expériences représentatives après le changement de régime. Aussi le mandat détenu par les députés élus prend-il une signification particulière : « Le mandat électif n'était pas une habilitation à représenter les intérêts des groupes sociaux mais une autorisation à libérer le député (au moins dans un sens) de la représentation de ces intérêts à l'avantage de la représentation de "l'intérêt de la réforme", défini (par l'élite politique) non seulement par la réforme économique de type libéral mais aussi comme une forme spécifique de renouveau moral de la société » (Bialecki \& Mach, 1992b, p. 183). L'exemple précédent est emblématique de la double dimension des textes réunis autour de l'analyse des représentations. Ces enquêtes ne font pas que rendre compte des opinions des élites. Elles sont également des contributions à l'analyse des manières de penser, de faire et d'être dans l'espace politique, constitutives du « métier politique».

\subsection{2. Élite et profession parlementaire : le regard des élites sur elles-mêmes}

Les analyses portant sur les représentations que se font les élites de la profession politique ou du rôle du député et celles consacrées à l'étude des pratiques politiques peuvent être également regroupées. Elles contribuent toutes à l'objectivation du « métier politique ». Quelles sont les caractéristiques des rôles politiques nouveaux qui se constituent au moment du changement de régime ? Quelle signification les individus qui les occupent leur attribuent-ils ? Comment rationalisent-ils leur présence parmi l'élite ? Ces questionnements sont particulièrement importants dans une conjoncture politique où l'on peut penser que l'institutionnalisation des rôles politiques, notamment représentatifs, suit un chemin long et sinueux.

L'analyse des représentations des élites n'a pas pour seul objectif de rendre compte de leurs positionnements politiques sur des enjeux sociaux. On interroge beaucoup certaines catégories dirigeantes, les députés au premier chef, sur la signification qu'elles attribuent à leurs activités politiques, au mandat détenu, etc. On étudie notamment les récits de l'accès au Parlement (Skotnicka-Illasiewicz, 1992 ; Pawlak, 1994) ainsi que les formes de rationalisation de l'engagement politique (Karpowicz, 1995). On cherche également à rendre compte des représentations que les députés se font du mandat qu'ils détiennent (Jackiewicz, 1992b) et du rôle qu'ils ont à jouer en tant que parlementaires dans le processus de transformation sociale (Stobinska, 1994 ; Jackiewicz, 1992a) et économique (Nalewajko, 1995). Dans une perspective proche, les élites sont également sollicitées pour verbaliser une représentation de l'élite politique. Irena Pankow pose à un groupe de députés en 1993 les trois questions suivantes : «Pouvez-vous 
nommer et décrire les acteurs les plus célèbres de la scène politique polonaise ? Est-ce que l'élite politique est consolidée par un quelconque intérêt commun, en dépit des différences idéologiques et biographiques ? Quel est cet intérêt commun ? » (Pankow, 1993, p. 167). Les opinions parlementaires sont dans certains cas recueillies sous la forme d'un bilan de la législature écoulée (Jackiewicz, 1994 ; Lelinska, 1995). On cherche à connaître également leurs vertus et leurs défauts (Post, 1994). Les députés sont encore interrogés sur la représentation qu'ils se font des différents aspects du métier politique. Quelle est leur compréhension du politique ? (Wesolowski, 1995). Ont-ils une conception normative de la profession politique ? (Post, 1992). Quelle est leur représentation de l'autorité ? (Mazurkiewicz, 1995). Enfin, les recherches d'Irena Pankow posent certaines des questions précédentes en appréhendant toutefois les parlementaires sous l'angle identitaire. Elle cherche notamment à connaître les effets de l'appartenance à l'élite parlementaire sur l'identité individuelle, d'abord auprès des députés de l'Assemblée contractuelle (Pankow, 1992) puis de la première législature (Pankow, 1994). La diversité des questions posées aux élites dissimule mal l'emploi récurrent d'une méthode unique. Mais d'autres recherches contribuent à enrichir notre connaissance du métier politique en Pologne.

\subsubsection{Profession et métier politiques : approches par les institutions}

En dépit de l'aspect hétéroclite de ce champ de questionnements - toute classification a une dimension arbitraire -, il est possible d'en extraire les préoccupations principales. Les recherches suivantes peuvent en effet être lues comme des contributions d'origine différente à la compréhension de l'institutionnalisation des rôles politiques en Pologne 53. La description de la genèse et des mécanismes d'encadrement légal des activités politiques rend compte des compétences, des droits et des devoirs prescrits par les institutions, à l'instar de la présentation de Jackiewicz du dispositif constitutionnel et législatif qui régule les activités des députés (Jackiewicz, 1994).

L'étude de l'organisation et de la place dans le champ politique des clubs parlementaires procède de la même préoccupation (Pawlak, 1992). Cependant, ces règles instituées ne découlent pas "naturellement" de la mise en place du nouveau régime. Elles sont au contraire soumises à de constantes actualisations. L'étude des activités des clubs parlementaires, des découpages politiques qui les différencient, des clivages qui structurent leur fonctionnement interne ainsi que des significations attribuées à cette institution par les élites elles-mêmes permet de rendre compte de la participation des élites

53. Force est de constater que cette préoccupation est encore marginale dans une sociologie polonaise très largement quantitativiste : «Le développement de modèles théoriques et de certains indices pour l'étude du "leadership politique" est un enjeu négligé de la sociologie et de la science politique d'Europe centrale » (WESOLOWSKI, 1999, p. 16). W. Wesolowski est l'un des rares sociologues polonais qui plaident pour le développement de l'étude, dans une optique wéberienne, des professionnels de la politique (MIELCZAREK \& WesOlowSKI, 1999 ; WESOLOWSKi, 1999). 
à l'institutionnalisation des rôles politiques. Elle nous rappelle que loin d'être la conséquence nécessaire du changement de régime, la distribution des responsabilités et des pouvoirs, la définition des rôles institutionnels procèdent de l'action d'élites relativement autonomes, insérées dans un contexte historique spécifique. Les élites sont les acteurs centraux de la fabrication des institutions, mais l'éventail des choix institutionnels est limité par les significations attribuées au changement politique. Catherine Castano montre par exemple l'importation de modèles institutionnels étrangers dans le processus de définition de l'institution présidentielle (Castano, 1993). Attentive tout à la fois à l'autonomie des acteurs et au contexte politico-institutionnel marqué par la valorisation des procédures démocratiques -, elle insiste sur la nécessité de "l'étude des trajectoires sociales, des dispositions, positions et ressources de ceux qui, dans leur pays respectif, vont tout à la fois se présenter, accéder au pouvoir et "faire" l'institution présidentielle " (Castano, 1993, pp. 250-251). À notre connaissance, ce type de recherche n'a pas été mené. Appartenant plus au genre de l'histoire politique qu'à l'analyse sociologique, l'article de Woytek Zubek sur le comportement politique de Lech Walesa durant son quinquennat présidentiel (1990-1995) apporte toutefois quelques éléments intéressants de compréhension des manières d'habiter le rôle présidentiel (Zubek, 1997). Étudiant Walesa sous le prisme de ses rapports avec les différentes forces politiques, l'auteur décrit la disqualification continue de l'ancien syndicaliste ouvrier (et figure historique de l'anticommunisme) dans la population polonaise. L'évolution du comportement de Lech Walesa, qu'on accuse de verser dans l'autoritarisme et le populisme, ce qui n'est pas sans conséquences sur la signification de l'institution et la place objective qu'elle occupe dans le système politique polonais, est ainsi rapportée à des causes extérieures à la personnalité de l'individu, tels que l'érosion de ses soutiens (ceux de Solidarité notamment et des intellectuels) et son manque de ressources légitimes pour occuper le mandat présidentiel (la maîtrise de la langue par exemple). Walesa est présenté comme l'emblème des évolutions qui affectent les élites politiques (le développement de la corruption en particulier) ${ }^{54}$. Il faut par conséquent se garder de souscrire à une pers-

54. Même s'il n'est pas psychologue, W. Zubek n'hésite cependant pas à décrire la « personnalité » de Walesa. Il reconnaît en effet l'importance de caractéristiques psychologiques dans la manière dont il occupe son poste et, ce faisant, contribue à construire l'institution présidentielle : « À bien des égards, la personnalité de Walesa était responsable de ce fiasco politique. Autoritaire par nature, le modèle politique de Walesa était davantage monarchique que démocratique, lui-même se considérant comme un "roi des paysans" qui voudrait le bien du peuple. Pendant les années 80 , ses tendances autoritaires ont été modérées par la lutte contre le gouvernement communiste (...) Une fois au pouvoir, les tendances autoritaires de Walesa sont venues à l'avant » (ZUBEK, 1997, p. 117). On trouve une systématisation de cette conception dans les travaux de Ray Taras consacrés aux « styles de leadership » des élites postcommunistes : «Les leaders, leurs personnalités et leurs styles affectent le caractère d'un système politique (...) Les styles de leadership - courtiers politiques, unificateurs, présidents impériaux, PDG, anti-leaders, leaders charismatiques - different profondément et influencent la nature du système politique » (TARAS, 1998, p. 105). 
pective trop étroitement institutionnaliste. Le caractère pluraliste du nouveau régime politique s'impose aux acteurs tout en restant à inventer. Pierre Kende critique le caractère " presque mécanique du nouveau consensus démocratique [en ce que] celui-ci, en effet, [serait] marqué par le présupposé selon lequel il suffit de se doter d'institutions conformes à la démocratie pour que la réalité se métamorphose aussitôt, ou très rapidement, dans le même sens. Ce présupposé pourrait être appelé "institutionnaliste" et c'est en ce sens que nous parlons ici d" "optimisme institutionnel" »(Kende, 1993). Destinée aux élites, la remarque peut s'appliquer aux chercheurs.

\subsubsection{Profession et professionnalisation politique : approches par les processus}

L'attention portée aux institutions politiques ne permet pas à elle seule de rendre compte de la formation du régime démocratique. C'est la raison pour laquelle certains aspects constitutifs du métier politique commencent à être étudiés, telles que les pratiques électorales saisies dans le nouveau contexte pluraliste (Raciborski, 1997) ou la corruption des gouvernants (Kaminski, 1997). L'un des axes d'étude du métier politique est celui de la profession politique. Il est sans doute plus approprié de parler de profession politique et non de professionnalisation dans la mesure où le régime communiste avait déjà suscité la formation d'une activité spécialisée, aux frontières du Parti et de l'État, dans des tâches "politiques". Le programme de recherche revient par conséquent à mesurer ce qui, dans le fonctionnement actuel de la profession politique, est le produit d'anciennes et de nouvelles règles du jeu politique, associées au fonctionnement d'une démocratie représentative. C'est la raison pour laquelle cette question est abordée notamment sous l'angle de la technicisation des activités politiques. Aleks Szczerbiak voit par exemple dans le recours croissant aux experts et aux consultants l'indice d'une professionnalisation des partis politiques polonais (Szczerbiak, 1998 ; Richard, 1998). Les députés ont été étudiés dans une perspective semblable (Post, 1995).

On peut cependant regretter que l'étude de la profession politique n'ait pas été élargie à l'analyse des rapports pratiques qui s'établissent entre les hommes politiques et les élites administratives 55 . Les relations entre les catégories dirigeantes et d'autres groupes sociaux forment une problématique solidement ancrée dans l'espace théorique polonais. L'analyse des rapports entre les élites et les groupes d'intérêt (Nalewajko, 1999), les élites et les syndicats (Pankow, 1999) est en effet un moyen de proposer une étude des intérêts sociaux incarnés

55. Les commentaires sont plus nombreux que les analyses. Cf. les opinions parues dans The Polish Sociological Bulletin, 1992. Une réflexion théorique existe également (KURCZEWSKA, 1991). 
et défendus par l'élite et d'interroger, au travers de ce prisme, le degré de consensus qui relie les élites. La composition de la haute administration a également été étudiée dans certaines enquêtes de morphologie des élites consacrées notamment au devenir de la nomenklatura sous le nouveau régime. Mais l'observation de la technicisation des activités politiques suppose que se développe davantage l'intérêt pour les modes de recrutement des hauts fonctionnaires, ainsi que le rôle qu'ils jouent dans le processus de prise de décision (Jackiewicz, 1999). Il faudrait également s'interroger sur le degré de politisation des élites administratives dans un contexte de disqualification de l'ancienne nomenklatura (Wiatr, 1995).

\subsection{ENTRE ANOMIE THÉORIQUE ET INDIFFÉRENCE SOCIOLOGIQUE : LE SORT RÉSERVÉ AUX ÉLITES LOCALES.}

Les effets du changement de régime sur l'intérêt porté aux élites politiques sont faibles concernant les élites locales. Il est vrai qu'en retour le rôle joué par ces dernières dans le changement de régime est relativement limité. Les décisions concernant la vie locale sont prises par les élites centrales puisqu'il faut, dans un premier temps, fonder les institutions administratives et représentatives qui forment le maillage politique du territoire. Le découpage entre élites locales et élites centrales mériterait toutefois d'être interrogé. Nous le reprenons ici dans la mesure où il est très prégnant dans la production sociologique : peu de travaux étudient en effet sous une même perspective les deux types d'élites. Le faible développement des phénomènes de cumul des mandats ou de "parachutage" en Pologne n'incite pas les chercheurs à analyser les élites insérées dans les segments nationaux du jeu politique au regard de leur implantation locale. Les ressources obtenues localement ne sont pas étudiées pour l'usage que des entrepreneurs politiques en font sur la scène nationale. À ce découpage théorique se superpose un clivage géographique. Les chercheurs de l'Académie polonaise des sciences étudient en premier lieu les élites parlementaires, gouvernementales, etc., tandis que les élites locales sont plus souvent étudiées dans des centres de recherche appartenant à des universités de province. L'ensemble des publications collectives de l'Académie polonaise des sciences est à cet égard emblématique du relatif désintérêt des sociologues varsoviens pour la dimension locale des activités politiques.

\subsubsection{Une relative indifférence}

Plusieurs raisons peuvent expliquer cette forme d'indifférence portée aux élites locales. Les difficultés d'accès aux sources peuvent être un obstacle pour des centres de recherche situés à Varsovie. On peut également y voir une conséquence du degré encore faible de décentralisation et d'institutionnalisation du rôle des acteurs politiques locaux : cela revient à conférer de la légitimité scientifique aux objets en fonction de leur épaisseur politique. Les élites locales sont sans doute également les victimes d'un rejet sociologique à l'égard d'un objet qui fut longtemps de consolation : les élites communistes ne toléraient en effet l'étude du pouvoir et du leadership que dans des segments localisés. Les recherches menées sur 
des objets locaux répondaient à des nécessités politiques 56. Les analyses étaient alors relativement nombreuses mais elles ne cherchaient pas à mettre en question l'efficacité des mécanismes représentatifs au niveau local. Si le recrutement des leaders communistes locaux a pu être étudié, les auteurs adoptaient une démarche étroitement descriptive. Celle-ci ne permettait pas d'aboutir à des conclusions susceptibles de remettre en cause le caractère fictionnel des procédures démocratiques de la Pologne populaire 57. Il est enfin possible de déceler dans cette situation les effets de certains positionnements théoriques qui, à l'instar du projet de Burton et Higley, valorisent l'étude des élites nationales. De plus, le changement de régime est considéré, là encore, comme un élément a priori déterminant, qui interdit d'appréhender l'espace local en continuité avec le régime précédent. La loi sur le gouvernement local de 1990, qui institue les collectivités territoriales, est constamment rappelée en préalable aux analyses. Ses modalités dessinent les circonstances institutionnelles qui déterminent notamment la nature des "trophées" politiques, les règles du jeu politique local et son fonctionnement réel.

Les questionnements auxquels sont soumises les élites locales sont en grande partie semblables aux problématiques définies pour les personnels politiques nationaux. À quelques différences près. Les formes d'exercice de l'activité politique locale sont par exemple absentes des préoccupations des chercheurs. Or il n'est pas imprudent de faire l'hypothèse, dans le cas de la Pologne, que se structurent et s'inventent des formes d'exercice de ce qui peut être appelé un «métier politique ». Le rôle du « président de ville », sorte de maire élu au suffrage indirect, peut constituer à cet égard un poste d'observation privilégié de la manière dont s'inventent et se stabilisent des pratiques politiques nouvelles. telles que la constitution de réseaux, l'agrégation de soutiens divers, l'élaboration d'une identité politique stratégique, etc. En réalité, les recherches dont nous

56. Les recherches portant sur le pouvoir local représentaient, sous le régime communiste, une part non négligeable de la sociologie politique polonaise. Les recherches étaient notamment menées par des équipes de l'Académie polonaise des sciences dirigées par Jerzy J. Wiatr. Un ouvrage publié en 1986 a été consacré au bilan de ce champ de recherche. Wiatr décline les raisons de la valorisation de l'objet local dans les enquêtes empiriques de l'époque : «Premièrement, les contraintes politiques rendaient difficile, sinon totalement impossible. d'étudier empiriquement beaucoup d'aspects de la politique nationale en raison, à la fois, de la limitation de l'accès aux données et de la restriction sur les publications (...) De plus, la politique locale, du fait du nombre d'éléments disponibles pour l'analyse, semblait s'adapter idéalement aux préoccupations de ceux qui, comme la plupart d'entre nous, étaient plus intéressés par des analyses comparées menant à des généralisations théoriques qu'à des analyses descriptives. Il y avait également une autre raison. Depuis de nombreuses années, les sociologues en Pologne cherchaient des possibilités de rendre leurs recherches pertinentes pour orienter la pratique politique. La recherche sur la politique locale semblait particulièrement importante dans cette perspective puisqu'elle nous permettait d'évaluer les réussites relatives et les échecs des autorités locales et d'évaluer de manière critique les conséquences du centralisme sur les niveaux inférieurs de l'administration en Pologne » (WIATR, 1986, pp. 5-6).

57. JASINSKA-KANIA \& SIEMIENSKA, 1982 ; JASINSKA-KANIA, 1986 ; OstrowsKi \& PRZEWORSKI, 1986 ; SIEMIENSKA, 1983 ; SIEMIENSKA, 1986a ; SiEMIENSKA, 1986b ; SiEMIENSKA \& TARKOWSKI, 1986 ; TARKOWSKI, WIATR \& ZAJORSKI, 1972 ; TARKOWSKI, 1978 ; TARKOWSKI, 1981 ; WIATR, 1967 ; WIATR, 1986 ; WIATR, 1987a ; WIATR, 1987b ; WIATR, 1987c ; BARTKOWSKI, 1992 ; BARTKOWSKI, 1996 ; WASILEWSKI, $1990 \mathrm{~b}$. 
avons eu connaissance s'appuient essentiellement sur des données morphologiques du personnel politique local. S'il est vrai que les « leaders locaux » qui constituent l'objet d'étude sont également interrogés sur leurs représentations, l'apport de cette méthode est relativement limité si elle n'est pas enrichie de l'observation des pratiques politiques des élites locales.

\subsubsection{Valeurs et représentations des «leaders locaux»}

Il est facile de comprendre, en fonction des remarques précédentes, que les élites locales soient questionnées davantage sur des enjeux économiques ou sociaux que sur la manière dont elles endossent les responsabilités qu'elles détiennent, sur les formes d'exercice du mandat, etc. Un certain nombre de recherches empiriques ont par exemple été menées depuis 1991 en Haute-Silésie sur la vie politique locale. On peut remarquer une dilution de l'intérêt pour les élites dans une approche plus globale de la démocratie locale (Pietrzko, 1994 ; Lyson, 1994 ; Sztumski, 1995). Wlodzimierz Lyson rend notamment compte d'une étude menée après les premières élections locales pluralistes en 1990 dans neuf communes situées dans la voïevodie 58 de Katowice, auprès de 153 leaders locaux, choisis selon ce qu'il appelle la méthode de position, c'est-à-dire, dans la perspective institutionnelle millsienne (Mills, 1969), en fonction de leur statut, de leur fonction, de leur mandat (Lyson, 1994) 59. Les résultats de l'étude confirme la nette exclusion des femmes de l'élite ainsi que la relative jeunesse des leaders locaux notée à propos des élites nationales. Il en est autrement du degré de formation. $58 \%$ seulement des élites sociales locales sont titulaires d'une formation supérieure. L'intelligentsia est néanmoins sur-représentée eu égard au poids qui est le sien dans la population des communes étudiées. Même si la structure hétérogène de l'échantillon nécessite de relativiser ces chiffres, il est toutefois intéressant de noter que si $22,9 \%$ des élites interrogées déclarent être affiliées à une organisation partisane ou syndicale, seules 2,6\% d'entre elles occuperaient un poste dans l'instance nationale et même "régionale" de leur organisation. L'auteur analyse ensuite les représentations des leaders locaux sur leur connaissance des problèmes qui se posent dans la commune et sur leur perception de leur capacité à les résoudre 60 .

58. Il s'agit d'une unité administrative. La Pologne est composée de seize voïvodies depuis le premier janvier 1998. Elle en comptait 49 au moment de l'étude.

59. L'échantillon est hétéroclite puisqu'il réunit aussi bien des maires et des maires adjoints que des entrepreneurs privés, des fonctionnaires, des directeurs d'entreprises publiques dans l'industrie, le commerce et les services, des directeurs d'école et de centres culturels ou de coopératives agricoles, des secrétaires de mairie.

60. Les travaux menés sous la direction de Jerzy Wiatr en 1991 et 1992 ont le mérite de s'appuyer sur une définition plus étroite des élites politiques locales. Prolongement d'une enquête de dimension internationale amorcée en 1966, la recherche effectuée par Aleksandra JasinskaKania et Jerzy Wiatr auprès d'un échantillon de 440 leaders (issus de collectivités locales dont la population se situe entre 25000 et 200000 habitants) confirme certains enseignements précédents. Là encore, il s'agit de rendre compte des caractéristiques de l'élite avant d'analyser ses représentations (JASINSKA-KANIA \& WIATR, 1986 ; JASINSKA-KANIA, 1998). 


\subsubsection{Trajectoires politiques et parcours sociaux}

Une autre série de recherches est davantage attentive à reconstituer les trajectoires suivies par les élites politiques locales. Jacek et Kazimiera Wodz cherchent par exemple à rendre compte des spécificités des modes d'accès au politique au niveau local en décrivant les types de «carrière » politique des leaders locaux (Wodz \& Wodz, 1996 ; Wodz, 1999) 61. Qu'il nous soit permis, dans ce cadre d'analyse, d'évoquer nos propres recherches en Pologne et singulièrement dans la voïevodie de Katowice (Heurtaux, 1998). Nous avons cherché à étudier les caractéristiques sociales et des parcours politiques des membres de l'élite politique locale afin de mettre en ćvidence l'existence d'indicateurs de rôle, au sens où l'entend Bailey, « que l'on estime compatibles ou incompatibles avec une activité politique » (Bailey, 1971, p. 37).

L'examen de ces critères "pragmatiques" de sélection du personnel politique n'a pas révélé une recomposition des ressources valorisées dans la compétition politique. L'analyse des biographies des députés et des maires de la voïevodie montre en effet que les critères de sélection de l'élite n'ont pas fondamentalement changé depuis la fin du régime communiste. Les membres de l'élite, comme l'élite communiste, sont relativement jeunes, de sexe masculin et disposent d'une compétence technique acquise pendant leur formation et approfondie au contact de leur profession. Les frontières du groupe dirigeant local ne seraient pas fermées aux anciens membres de l'élite détenteurs des ressources sociales valorisées. Les frontières de l'élite seraient davantage imperméables aux syndicalistes ouvriers qu'aux ex-communistes. En définitive, si les membres de l'élite ont été renouvelés, ils l'ont été partiellement, la moitié n'ayant jamais occupé auparavant de fonction élective. L'autre moitié est issue d'un parcours ambivalcnt sous le régime communiste : elle comprend des individus qui ont « fait de la politique » dans des circonstances politiques imposées. Ils n'ont donc pas hésité à continuer dans un contexte démocratique qu'ils ont eux-mêmes contribué à créer. Il convient toutefois de prolonger ce champ de recherche par l'analyse des formes de légitimation des leaders politiques locaux afin d'élargir l'étude du métier politique en Pologne à ses dimensions localisées.

\section{CONCLUSION}

À la lecture de la recherche sociologique sur les élites politiques polonaises, on observe une forme de division internationale du travail scientifique : les sociographies de personnels politiques sont essentiellement des travaux polonais, les recherches étrangères, notamment anglo-saxonnes, s'intéressant davantage aux processus transitionnels. En dépit de la diversité des questionnements et de la variété apparente de l'objet, les premières partagent des traits communs :

61. Sur les modes de sélection des élites locales, se reporter également à BuKowskı, 1996. 
des rapports étroits avec le monde politique, un usage ambigu de certaines ressources théoriques, l'emploi d'une méthode exclusive. En définitive, l'autonomie de la sociologie polonaise est toute relative : elle "subit" et utilise conjointement la science politique américaine. Mais si certaines macro-théories l'entraînent sur les pentes dangereuses de la transitologie, elle leur oppose pourtant l'attachement à des enquêtes empiriques approfondies. La frénésie élitaire dans les sciences sociales polonaises reste cependant dominée par des questionnements théoriques relativement pauvres, non dénués d'une dimension téléologique. Les élites universitaires et les élites politiques regardent en effet dans la même direction, espèrent l'horizon démocratique. Ces éléments concourent au développement d'un schème "démocratiste" dont il faut pourtant se libérer.

L'une des pistes possibles d'analyse du personnel dirigeant en Europe centrale postcommuniste, en essayant d'échapper à ces pièges, peut être d'analyser ses modes de légitimation. Dans une société qui redécouvre les procédures de représentation démocratique, la question des fondements de la légitimité du « groupe ou de l'individu qui exerce effectivement le pouvoir, étant donné que sa légitimité peut être contestée alors même que les procédures de désignation lui ont été scrupuleusement appliquées » (Lagroye, 1984) est essentielle. Comment les élites politiques se légitiment-elles dans une société postcommuniste telle que la Pologne? Il faudrait, pour y répondre, rendre compte des processus de sélection et d'institutionnalisation des ressources sociales et des propriétés politiques fonctionnant comme des critères d'habilitation à l'exercice d'un mandat politique qui autorisent à se porter candidat. Dans quelle mesure, par exemple, un passé de syndicaliste ouvrier dans Solidarité, généralement associé à une forme d'incompétence dans l'exercice des affaires publiques, reste-t-il un attribut favorable dans une société qui a progressivement reconnu la qualité de la formation et l'expérience des anciens communistes reconvertis dans la social-démocratie ? L'appartenance à l'intelligentsia constitue-t-elle une qualité valorisée dans la compétition politique ? Cette ressource ne devient-elle pas essentielle dans un contexte où la diffusion des valeurs libérales, la promotion de l'individualisme et le rejet de l'égalitarisme conjuguent leurs effets? Les propriétés légitimes sont en réalité sans cesse redéfinies. Les bornes de ce qu'on pourrait nommer la compétence politique légitime sont un enjeu permanent, enjeu de conflits entre acteurs et groupes d'acteurs.

Tout contexte de changement de régime produit, selon Michel Offerlé, « un réajustement (momentané ou durable) des propriétés du personnel politique et de sa légitimation »(Offerlé, 1999, p. 25). Il faudrait alors étudier la diversité des usages que les hommes politiques font de leurs propriétés dans la compétition politique, quelles sont les caractéristiques les plus valorisées, dans quelle mesure elles diffèrent en fonction de l'appartenance politique ou du contexte étudié, etc. Il faudrait en définitive appréhender conjointement les qualités constitutives de la compétence politique et les ressources susceptibles d'expliquer l'entrée en politique. La situation polonaise exige en effet d'analyser tant les formes de légitimation des individus que les manières dont on pratique le métier politique. La 
problématique de la légitimation a partie liée avec le thème de la profession politique (Heurtaux, 1999). Cette focale d'analyse peut être pertinente en ce qu'elle permet de disséquer tant l'invention de nouvelles formes d'échange politique, à l'image des procédures de représentation démocratique, que les formes de légitimité sur lesquelles ces échanges s'appuient. 


\section{BIBLIOGRAPHIE}

\section{Élites, structure sociale et stratification sociale sous le communisme}

BIEZENSKI R. (1996), "The Struggle for Solidarity 1980-1981: Two Waves of Leadership in Conflict", Europe-Asia Studies, Vol. 48, n 2, pp. 261-284.

CONNElly J. (1996), "Foundations for Reconstructing Elites. Communist Higher Educational Policies in the Czech Lands, East Germany and Poland, 1945-48", East European Politics and Societies, $\mathrm{n}^{\circ} 3$, pp. 367-392.

Dullas M. (1957), The New Class. An analysis of the Communist System, London.

Hochfeld J. (1962), “In Memory of Cecil Wright Mills”, The Polish Sociological Bulletin, $\mathrm{n}^{\circ}$ 1-2, pp. 5-7.

Kende P. \& Strmiska Z. (1984), Égalité et inégalités en Europe de l'Est, Paris : Presses de la Fondation nationale des sciences politiques.

Kurczewski J. (1998), “A Self-Commissioned Sociology for the People: Ossowski on Marxism and Marxist Societies", Polish Sociological Review, $\mathrm{n}^{\circ} 2$, pp. 95-113.

Kuron J. \& Modzelewski K. (1968), Lettre ouverte au Parti Polonais, Supplément à Quatrième Internationale, $\mathrm{n}^{\circ} 32$.

LAZARZ B. (1997), Legitymizacja wlasnej wladzy - spojrzenie przywodsow PRL na swoja biografie polityczna z perspektywy lat dziewiecdziesiatych (La légitimation de son propre pouvoir - le regard des dirigeants de la PRL dans les biographies politiques dans la perspective des années quatre-vingt-dix), Kultura i Spoleczenstwo, $\mathrm{n}^{\circ} 4$, pp. 97-115.

Lewis P. G. (1989), Political Authority and Party Secretaries in Poland 1975-1986, Cambridge : Cambridge University Press.

MARKIEWICZ-LaGNeAu J. (1969), Education, égalité et socialisme. Théorie et pratique de la différenciation sociale en pays socialistes, Paris : Anthropos.

Mink G. (1982a), "Compte-rendu du VIe congrès national de sociologie polonaise (Lodz : 9-12 septembre 1981)", Revue d'études comparatives est-ouest, vol. XIII, $\mathrm{n}^{\circ} 1$, pp. 157-164.

Mink G. (1982b), "Approches de la structure sociale en Pologne : du dogme unique au pluralisme d'écoles", Revue d'études comparatives est-ouest, vol. XIII, ${ }^{\circ} 4$, pp. 129155.

Narkiewicz O A. (1990), Petrification and Progress. Communist Leaders in Eastern Europe, 1956-1988, Londres: Harvester Wheatsheaf.

Ossowski S. (1971), La structure de classes dans la conscience sociale, Paris : Anthropos (1ère édition, 1963).

PASzTOR M., en collaboration avec JAROSZ D. (1999), "Les caractéristiques sociales des élites au pouvoir sous Biérut (1948-1956), in E. du Réau, Europe des élites ? Europe des peuples? La construction de l'espace européen. 1945-1960, Paris : Presses de la Sorbonne nouvelle, pp. 113-119.

SLOMCZYNSKi K. M. \& Wesolowski W. (1977), Investigations on Class Structure and Social Stratification in Poland, 1945-1975, Warszawa.

SZELENYI I. (1978), "La position de l'intelligentsia dans la structure de classe des sociétés socialistes d'État", Actes de la recherche en sciences sociales, 22, pp. 61-74.

Wasilewski J. (1990a), "The Patterns of Bureaucratic Elite Recruitment in Poland in the 1970s and 1980s", Soviet Studies, Vol. 42, n 4, pp. 743-757. 
Wesolowski W. (1966), Klasy, warstwy $i$ wladza (Classes, strates et pouvoir), Warszawa.

Wiatr J. J. (1973), "Political Elites and Political Leadership: Conceptual Problems and Selected Hypotheses for Comparative Research", in J. J. Wiatr (1978), Essays in Political Sociology, Warszawa : Ossolineum, pp. 91-109.

Wiatr J. J. (1974), Past and Present in Polish Sociology, Warszawa : Wydawnictwo PAN.

WiATR J. J. (1987a), "Biography of the Statesman as Sociological Material", The Polish Sociological Bulletin, ${ }^{\circ} 1$, pp. 19-37.

WiATR J. J. (1987b), "Political Leadership in Poland in Light of Sociological Research", The Polish Sociological Bulletin, $\mathrm{n}^{\circ}$ 2, pp. 69-81.

WoJcik P., wyd. (1989), Elity wladzy w Polsce a struktura spoleczna w latach 1944-1956 (Les élites de pouvoir en Pologne et la structure sociale 1944-1956), Warszawa : Polska Agencja Prasowa.

WoJcIK P., wyd. (1994), Elity wladzy w Polsce a struktura spoleczna w latach 1956-1981 (Les élites de pouvoir en Pologne et la structure sociale 1956-1981), Warszawa : Polska Agencja Prasowa.

\section{“Transition", changement politique, acteurs politiques en Pologne}

Blaszkiewicz A., Rykowski Z. W., SzWajcer P. \& Wertenstein-Zulawski J. (1994), "The Solidarnosc Spring ?", Communist and Post-communist Studies, n² 2, pp. 125-134.

Blazyca G. \& RAPACKI R. (1991), Poland into the 1990s: Economy and Society in Transition, London : Pinter.

Burawoy M. \& Lukacs J. (1992), The Radiant Past: Ideology and Reality in Hungary's Road to Capitalism, Chicago : University of Chicago Press.

Castano C. (1993), "La construction de l'institution présidentielle dans les pays de l'Est (Bulgarie, Hongrie, Pologne, Roumanie, Tchécoslovaquie)”, in Y. Mény, dir., La greffe et le rejet. La politique du mimétisme institutionnel, Paris : L'Harmattan, pp. 249-283.

Clark J. \& Wildavski A. (1990), The Moral Collapse of Communism: Bland as a Cautionary Tale, San Francisco : Institute for Contemporary Studies Press.

Colomer J. M. \& Pascual M. (1994), "The Polish Games of Transition", Communist and Post-Communist Studies, $\mathbf{n}^{\circ} 3$, pp. 275-294.

Crawford B. \& Lijphart A. (1995), "Explaining Political and Economic Change in Post-Communist Eastern Europe. Old Legacies, New Institutions, Hegemonic Norms and International Pressures", Comparative Political Studies, n² 2, pp. 171-199.

Diamond L. \& Plattner M. F. (1995), Economic Reform and Democracy, Baltimore : The John Hopkins University Press.

Dimitrova B. (1996), "La transition bulgare à la démocratie", Revue internationale de politique comparée, $\mathrm{n}^{\circ} 1$, pp. 107-115.

FRYBES M. (1993), "Le syndicalisme en Europe centrale, à la recherche d'une nouvelle légitimité sociale et politique", Cahiers internationaux de sociologie, $\mathrm{n}^{\circ} \mathrm{XCV}, \mathrm{pp} .275-287$.

Frybes M. \& Michel P. (1996), Après le communisme, mythes et légendes de la Pologne contemporaine, Paris : Bayard Éditions.

Goodwyn L. (1991), Breaking The Barrier: The Rise of Solidarity in Poland, Oxford : Oxford University Press.

Grabowska M. (1993), "Political Parties in Post-communist Poland: Disenchantments and Uncertain Chances", Sisyphus, ${ }^{\circ}$ 1, pp. 55-74.

Haggard S. \& Kaufman R. R. (1995), The Political Economy of Democratic Transitions, Princeton : Princeton University Press. 
HERMET G. (2000), "Le charme trompeur des théories. Un état des travaux", in C. Jaffrelot, dir., Démocraties d'ailleurs, Paris : Karthala, pp. 315-342.

HEYNS B. \& BiAlecki I. (1991), "Solidarnosc: Reluctant Vanguard or Makeshift Coalition?", American Political Science Review, n² 2, pp. 351-376.

Hirschman A. O. (1995), Un certain penchant à l'autosubversion, Paris : Fayard.

Hovacs J. M. \& TARdos M. (1992), Reform and Transformation in Eastern Europe: Soviet-type Economics on the Threshold of Change, New York : Routledge.

Kaminski A. (1992), An Institutional Theory of Communist Regimes: Design, Function, and Breakdown, San Francisco : Institute for Comparative Studies.

Kaminski B. (1991), The Collapse of State Socialism: The Case of Poland, Princeton : Princeton University Press.

KENDE P. (1996), “La démocratie libérale, réponse adéquate aux problèmes nés de la 'transition' ?", Revue internationale de politique comparée, $\mathrm{n}^{\circ}$ 1, pp. 1I-19.

Kende P. \& SMOlaR A., dir. (1990), La grande secousse. Europe de l'Est 1989-1990, Paris : Presses du CNRS.

Kitschelt H. (1992), "Political Regime Change: Structure and Process-driven Explanations?", American Political Science Review, n4, pp. 1021-1034.

LABA R. (1991), The Roots of Solidarity: A Political Sociology of Poland's Working Class Democratization, Princeton : Princeton University Press.

LEwIS P. G. (1994), "Political Institutionalisation and Party Development in Post-communist Poland", Europe-Asia Studies, Vol. 46, n 5, pp. 779-799.

Linz J. J. \& Stepan A. (1996), Problems of Democratic Transition and Consolidation. Southern Europe, South America, and Post-Communist Europe, Baltimore : The John Hopkins University Press.

LyNN Karl T. L. \& SCHMiTTER P. (1991), "Les modes de transition en Amérique latine, en Europe du Sud et de l'Est", Revue internationale des sciences sociales, $\mathrm{n}^{\circ} 128$, pp. 285-302.

Marody M. (1995), “Three Stages of Party System Emergence in Poland", Communist and Post-communist Studies, $\mathrm{n}^{\circ} 2$, pp. 263-270.

MiChel P. (1994), “De la nature de la 'transition' : remarques épistémologiques", Cahiers internationaux de sociologie, $\mathrm{n}^{\circ}$ XCVI, pp. 213-224.

Milacic S. (1996), "Critique de la transition unique. Notre épistémologie du post-communisme dans le rétroviseur de la pensée unique", Revue internationale de politique comparée, $\mathrm{n}^{\circ} 1$, pp. 19-40.

Molnar M. (1990), La démocratie se lève à l'Est. Société civile et communisme en Europe de l'Est: Pologne et Hongrie, Paris : Presses Universitaires de France.

O'Donnel G. \& SChMitTer P. (1993), Transitions from Authoritarian Rule. Tentative Conclusions about Uncertain Democracies, Baltimore : The John Hopkins University Press.

OFFE C. (1992), "Vers le capitalisme par construction démocratique ? La théorie de la démocratie et la triple transition en Europe de l'Est", Revue française de science politique, $\mathrm{n}^{\circ} 6$, pp. 923-942.

Ost D. (1990), Solidarity and the Politics of Anti-politics: Opposition and Reform in Poland since 1968, Philadelphia : Temple University Press.

PACZKowski A. (1995), “The 'Great Historical Experiment' or the Demise of Real Socialism in Poland", in E. Wnuk-Lipinski, Ed., After Communism, a Multidisciplinary Approach of Radical Social Change, Warsaw : PAN-ISP, pp. 57-66.

PodGorecki A. (1991a), “A Concise Theory of Post-Totalitarianism (Poland - 1989/1990)", The Polish Sociological Bulletin, $\mathrm{n}^{\circ} 2$, pp. 89-100. 
PrzeWorski A. (1991), Democracy and the Market: Political and Economic Reforms in Eastern Europe and Latin America, New York : Cambridge University Press.

RACIBORSKI J. (1997), Polskie Wybory. Zachowania wyborcze spoleczenstwa polskiego 1989-1995 (Les élections polonaises. Les comportements électoraux de la société polonaise 1989-1995), Warszawa : Wydawnictwo Naukowe "Scholar".

RAmet S. (1992), Social Currents in Eastern Europe: The Sources and Meaning of the Great Transformation, Durham : Duke University Press.

RichaRd F. (1998), L'union de la Liberté sur la scène politique polonaise. D'un club d'intellectuels issu de la dissidence à un parti libéral ?, Mémoire de DEA, IEP Paris.

Roszkowskı W. (1995), "From Communism to Where?", in E. Wnuk-Lipinski, Ed., After Communism, a Multidisciplinary Approach of Radical Social Change, Warsaw : PANISP, pp. 203-212.

Rozman G. (1992), Dismantling Communism: Common Causes and Regional Variations, Baltimore : The John Hopkins University Press.

SANTISO J. (1996), "De la condition historique des transitologues en Amérique latine et Europe centrale et orientale", Revue internationale de politique comparée, $\mathrm{n}^{\circ} 1$, pp. 41-68.

Staniszkis J. (1984), Pologne. Une Révolution auto-limitée, Paris : Presses Universitaires de France.

Staniszkis J. (1991), The Dynamics of the Breakthrough in Eastern Europe: The Polish Experience, Berkeley : University of California Press.

STANISZKIS J. (1995), "In search of a paradigm of transformation", in E. Wnuk-Lipinski, Ed., After Communism, a Multidisciplinary Approach of Radical Social Change, Warsaw : PAN-ISP, pp. 19-55.

Szczerbiak A. (1998), "Bureaucrats and Professionals. The 'Party-Machine' in PostCommunist Poland", Research Joint Sessions of Workshops, Mannheim.

Szklarski B. (1993), "Party Non-system. Nascent Political Parties, Elites, and the Electorate", Sisyphus, ${ }^{\circ} 1$, pp. 33-53.

Tismaneanu V. (1992), Reinventing Politics: Eastern Europe from Stalin to Havel, New York : Free Press.

Touraine A., Dubet F., Wieviorka M. \& Strzelecki J. (1982), Solidarité, analyse d'un mouvement social, Pologne 1980-1981, Paris : Fayard.

Wesolowski W. (1993), "Formation of Political Parties in Post-communist Poland", Sisyphus, $\mathrm{n}^{\circ}$ 1, pp. 9-32.

Wiatr J. J. (1993), "Fragmented Parties in a New Democracy: Poland", in J. J. Wiatr, Ed., The Politics of Democratic Transformation. Poland After 1989, Warsaw : Scholar Agency.

WNUK-LIPINSKI E., Ed. (1995a), After Communism, a Multidisciplinary Approach of Radical Social Change, Warsaw : PAN-ISP.

WNUK-LIPINSKI E. (1995b), "Is a Theory of Post-communist Transformation Possible?", in E. Wnuk-Lipinski, Ed., After Communism, a Multidisciplinary Approach of Radical Social Change, Warsaw : PAN-ISP, pp. 5-18.

Zubek V. (1994), "The Reassertion of the Left in Post-communist Poland", Europe-Asia Studies, Vol. 46, n 5, pp. 801-837.

Zubek V. (1995), "The Phoenix Out the Ashes: The Rise to Power of Poland's Post-communist SdRP”, Communist and Post-communist Studies, ${ }^{\circ} 3$, pp. 275-306. 


\section{Élites nationales postcommunistes}

Baylis T. A. (1994), "Plus Ça Change? Transformation and Continuity Among East European Elites", Communist and Post-Communist Studies, $\mathrm{n}^{\circ} 27$, pp. 315-328.

BIALECKI I. \& MACH B. W. (1992a), Orientacje spoleczno-ekonomiczne poslow na tle pogladow spoleczenstwa (Les orientations socio-économiques des députés au regard des opinions de la société), in J. Wasilewski \& W. Wesolowski, wyd., Poczatki parlamentarnej elity. Poslowie kontraktowego Sejmu (Les débuts de l'élite parlementaire. Les députés de l'Assemblée contractuelle), Warszawa : Wydawnictwo IFiS PAN, pp. 119-156.

Bialecki I. \& MACH B W. (1992b), "The Social and Economic Orientations of Polish Legislators. Against a Background of the Views of Polish Society", The Polish Sociological Bulletin, $\mathrm{n}^{\circ} 2$, pp. 167-186.

BLEJER M. I. \& CORICELli F. (1995), The Making of Economic Reform in Eastern Europe. Conversations with Leading Reformers in Poland, Hungary and the Czech Republic, Aldershot, Brookfield : Elgar.

BOROCZ J. \& RonA-TAS A. (1995), "Small Leap Forward. Emergence of New Economic Elites", in Theory and Society, $\mathrm{n}^{\circ}$ 5, pp. 751-781.

Chmatko N. \& Saint-Martin M. DE (1997), “Les anciens bureaucrates dans l'économie de marché en Russie”, Genèses, n² 27, pp. 88-108.

Drag Z. (1999), Elita biznesu. Autonomiczny segment elity politycznej ? (L'élite économique. Un segment autonome de l'élite politique ?), in J. Wasilewski, wyd., Elita polityczna 1998. Raport wstepny $z$ badan "Elita rzadzaca i wladza elity" (L'élite politique 1998. Rapport liminaire de la.recherche "L'élite gouvernante et l'élite du pouvoir"), Warszawa : ISP PAN, pp. 57-74.

Etzioni-Halevy E. (1998), "The Relationship between Elites and the Working Class. On Coupling, Uncoupling, Democracy and [In]Equality", in J. Highley, J. Pakulski J. \& W. Wesolowski, Postcommunist Elites and Democracy in Eastern Europe, New York : St. Martin's Press, pp. 251-276.

Eyal G. \& Townsley E. (1995), "The Social Composition of the Communist Nomenklatura. A Comparison of Russia, Poland, and Hungary", in Theory and Society, Special Issue on Circulation vs. Reproduction of Elites during the Post-Communist Transformation on Eastern Europe, ${ }^{\circ}$ 5, pp. 723-750.

Fodor E., WNuk-Lipinski E. \& Yershova N. (1995), "The New Political and Cultural Elite", in Theory and Society, Special Issue on Circulation vs. Reproduction of Elites during the Post-Communist Transformation on Eastern Europe, $n^{\circ}$ 5, pp. 783-800.

GORTAT R. (1995), Obraz spoleczenstwa polskiego. Zroznicowanie i czynniki integrujace (L'image de la société polonaise. Éléments de différenciation et d'intégration), in I. Pankow \& W. Wesolowski, wyd., Swiat elity politycznej (Le monde de l'élite politique), Warszawa : Wydawnictwo IFiS PAN, pp. 37-79.

Grabowska M. \& Szawiel T. (1993), Anatomia elit politycznych. Partie polityczne w postkomunistycznej Polsce 1991-93 (Anatomie des élites politiques. Les partis politiques en Pologne postcommuniste 1991-93), Warszawa : Instytut Socjologii Uniwersytetu Warszawskiego.

Heurtaux J. (1999), “The Emergence of a New Model of Political Profession in Poland. Empirical and Theoretical Proposals", communication au workshop «The Second Generation of Democratic Elites in Eastern and Central Europe », Mogilany, 10-12 décembre.

Higley J. \& PAKUlski J. (1992), Rewolucje i transformacje elit wladzy w Europie Wschodniej (Révolutions et transformations de l'élite du pouvoir en Europe de l'Est), Kultura i Spoleczenstwo, ${ }^{\circ} 2$, pp. 19-35. 
Highley J., Pakulski J. \& Wesolowski W. (1998a), Postcommunist Elites and Democracy in Eastern Europe, New York : St. Martin's Press.

Highley J., Pakulski J. \& Wesolowski W. (1998b), "Introduction. Elite Change and Democratic Regimes in Eastern Europe”, in J. Highley, J. Pakulski \& W. Wesolowski, op. cit., New York : St. Martin's Press, pp. 1-33.

JACKIEWICZ I. (1992a), Poslowie okresu transformacji, czyli postawa rycerska i pasozytnicza polskiej elity politycznej (Les députés dans la période de transformation. Attitudes chevaleresques et parasitaires de l'élite politique polonaise), in $\mathrm{K}$. Palecki, wyd., Elity polityczne w Polsce (Les élites politiques en Pologne), Warszawa : Zarzad Glowny Polskie Towarzystwo Nauk Politycznych, pp. 268-278.

JACKIEWICZ I. (1992b), "Wykonuje swoj mandat zgodnie z ich wola..." ? Role poselskie $w$ Sejmie $X$ kadencji ("Remplir son mandat conformément à sa volonté..." ? Les rôles des députés dans la Diète sous la dixième législature), in J. Wasilewski \& W. Wesolowski, wyd., Poczatki parlamentarnej elity. Poslowie kontraktowego Sejmu (Les débuts de l'élite parlementaire. Les députés de l'Assemblée contractuelle), Warszawa : Wydawnictwo IFiS PAN, pp. 193-228.

JACKIEWICZ I. (1994a), Parlament $w$ procesie transformacji. Sejm kontraktowy $i$ Sejm I kadencji (Le Parlement dans le processus de transformation. La Diète contractuelle et la Diète de la première législature), in J. Wasilewski, wyd., Konsolidacja elit politycznych 1991-1993 (La consolidation des élites politiques 1991-1993), Warszawa : ISP PAN, pp. 129-161.

JACKIEWICZ Z. (1994b), Regulacje prawne zachowan poselskich (La réglementation des droits et des attitudes des députés), in J. Wasilewski, wyd., Konsolidacja elit politycznych 1991-1993 (La consolidation des élites politiques 1991-1993), Warszawa : ISP PAN, pp. 51-67.

JaCKIEWICZ I. (1996), Nowe role w nowym Sejmie. Poslowie Sejmu okresu transformacji 1989-1993 (Nouveaux rôles dans une nouvelle Diète. Les députés de la Diète dans la période de transformation 1989-1993), Warszawa : Wydawnictwo Sejmowe.

JACKIEWICZ I. (1999), Elita $w$ procesie podejmowania decyzji. Stratedzy czy lobbysci? (L'élite dans le processus de prise de décision. Stratèges ou lobbyistes ?), in J. Wasilewski, wyd., Elita polityczna 1998. Raport wstepny z badan "Elita rzadzaca $i$ wladza elity" (L'élite politique 1998. Rapport liminaire de la recherche "L'élite gouvernante et l'élite du pouvoir"), Warszawa : ISP PAN, pp. 104-123.

Kaminski A. Z. (1997), "Corruption Under the Post-Communist Transformation. The Case of Poland", Polish Sociological Review, ${ }^{\circ} 2$, pp. 91-117.

Karpowicz E. (1995), Motywy kandydowania do Sejmu (Les motifs des candidatures à la Diète), in I. Pankow \& W. Wesolowski, wyd., Swiat elity politycznej (Le monde de l'élite politique), Warszawa : Wydawnictwo IFiS PAN, pp. 275-298.

KENDE P. (1993), "L'optimisme institutionnel des élites postcommunistes", in Y. Mény, dir., La greffe et le rejet. La politique du mimétisme institutionnel, Paris : L'Harmattan, pp. 237-247.

Kurczewska J. (1991), "Technocrats and Politics", The Polish Sociological Bulletin, $\mathrm{n}^{\circ}$ 1, pp. 63-74.

Kurczewska J. (1996), "Party Leaders Facing Poland's Past and Culture", Polish Sociological Review, $\mathrm{n}^{\circ} 4$, pp. 365-380.

Kurczewska J. \& Kaminski A. Z. (1992), "Political Meandering", The Polish Sociological Bulletin, $\mathrm{n}^{\circ} 2$, pp. 59-62.

LELINSKA K. (1995), Sejm I kadencji w swiadomosci poslow (La Diète de la première législature dans le souvenir des députés), in I. Pankow \& W. Wesolowski, wyd., Swiat elity politycznej (Le monde de l'élite politique), Warszawa : Wydawnictwo IFiS PAN, pp. 299-370. 
Marianski J. (1992), Czy kosciol katolicki w Polsce jest sila polityczna ? (L'Église catholique est-elle une force politique en Pologne ?), in K. Palecki, wyd., Elity polityczne w Polsce (Les élites politiques en Pologne), Warszawa : Zarzad Glowny Polskie Towarzystwo Nauk Politycznych, pp. 213-228.

Matonyte I. (1998), “Grilles d'analyse de l'élite économique post-soviétique", Revue d'études comparatives est-ouest, vol. 29, n 1, pp. 97-119.

Matonyte I. (1999), Sociological Interpretations of Elite and their Use in the Post-Soviet Area. Abstract of Doctoral Thesis, Kaunas : Vytauto Didziojo Universitetas.

MAZURKIEwicz L. (1995), Poselskie wizje przywodztwa politycznego : wodz, autorytet, menedzer polityczny (Les visions des députés du commandement politique : leadership, autorité, chefs politiques), in I. Pankow \& W. Wesolowski, wyd., Swiat elity politycznej (Le monde de l'élite politique), Warszawa : Wydawnictwo IFiS PAN, pp. 219-234.

MielczareK P. \& WesolowsKi W. (1999), Zmiennosc i stabilizacja warstwy politycznej. Cztery sejmy okresu transformacji (Instabilité et stabilisation de la classe politique. Les quatre assemblées de la période de transformation), Studia socjologiczne, $\mathrm{n}^{\circ} 3$.

MiNk G. (1993), "Les mystères de l'acteur invisible. Remarques sur l'hypothèse du retour des communistes en Europe Centrale et Orientale", Cahiers internationaux de sociologie, $\mathrm{n}^{\circ} \mathrm{XCV}$, pp. 417-433.

Mink G. \& Szurek J.-C. (1992a), "Ruptures et transitions”, in G. Mink \& J.-C. Szurek, dir., Cet étrange post-communisme. Rupture et transitions en Europe centrale et orientale, Paris : La Découverte, pp. 7-13.

Mink G. \& Szurek J.-C. (1992b), “Adaptation et stratégies de conversion des anciennes élites communistes", in G. Mink \& J.-C. Szurek, dir., Cet étrange post-communisme. Rupture et transitions en Europe centrale et orientale, Paris : La Découverte, pp. 67-83.

Mink G. \& Szurek J.-C., éds. (1993), "Les anciennes et les nouvelles élites en Europe centrale et orientale", Problèmes politiques et sociaux, La documentation française, n 703 (numéro spécial).

Mink G. \& SzurEK J.-C. (1994a), "Agir ou subir : les nomenklaturas polonaise et tchèque face à la grande mutation économique (1988-1993)", Revue d'études comparatives Est-Ouest, vol. $25, \mathrm{n}^{\circ} 4$, pp. 47-64.

Mink G. \& SzUREK J.-C. (1994b), "Fin de règne : trois conservateurs parlent de 1989 (Karoly Grosz, Leszek Miller, Miroslav Stepan)", L'Autre Europe, n 28-29, pp. 64-80.

Mink G. \& SzUreK J.-C. (1995), "De la nomenklatura polonaise aux élites économiques de l'après-communisme", in E. Suleiman \& M. Mendras, Le recrutement des élites en Europe, Paris : Presses du CNRS - La Découverte, pp. 211-228.

Mink G. \& SzUREK J.-C. (1998), “L'ancienne élite communiste en Europe centrale : stratégies, ressources et reconstructions identitaires", Revue française de science politique, $\mathrm{n}^{\circ}$ 1, pp. 3-41.

Mink G. \& Szurek J.-C. (1999a), "Conversion économique des anciennes élites en Europe Centrale", in F. Daucé \& G. Favarel-Garrigues, Actes du colloque «Stratégies et acteurs locaux dans l'Europe post-communiste ", 29-30 janvier 1998, Cahiers Leroy-Beaulieu, pp. 189-194.

Mink G. \& SzUREK J.-C. (1999b), La grande conversion. Le destin des communistes en Europe de l'Est, Paris : Éditions du Seuil.

Nalewajko E. (1992), Poslowie Sejmu X kadencji. Charakterystyka ogolne (Les députés de la Diète de la dixième législature. Caractéristiques générales), in J. Wasilewski $\&$ W. Wesolowski, wyd., Poczatki parlamentarnej elity. Poslowie kontraktowego Sejmu (Les débuts de l'élite parlementaire. Les députés de l'Assemblée contractuelle), Warszawa : Wydawnictwo IFiS PAN, pp. 73-96. 
Nalewajko E. (1995), Polityka i gospodarka - percepcja roli prawodawczy (Politique et économie - la perception des rôles législatifs), in I. Pankow \& W. Wesolowski, wyd., Swiat elity politycznej (Le monde de l'élite politique), Warszawa : Wydawnictwo IFiS PAN, pp. 255-274.

NALEWAJKo E. (1999), Wladza i interesy. Elity wobec grupowych naciskow (Pouvoir et intérêts. Les élites face aux groupes d'intérêts), in J. Wasilewski, wyd., Elita polityczna 1998. Raport wstepny $z$ badan "Elita rzadzaca $i$ wladza elity" (L'élite politique 1998. Rapport liminaire de la recherche "L'élite gouvernante et l'élite du pouvoir"), Warszawa : ISP PAN, pp. 89-108.

Palecki K., wyd. (1992), Elity polityczne w Polsce (Les élites politiques en Pologne), Warszawa : Zarzad Glowny Polskie Towarzystwo Nauk Politycznych.

Pankow I. (1992), Poslowie Sejmu X kadencji. Fenomen tozsamosci politycznej (Les députés de la dixième législature. Le phénomène d'identité politique), in $\mathrm{J}$. Wasilewski \& W. Wesolowski, wyd., Poczatki parlamentarnej elity. Poslowie kontraktowego Sejmu (Les débuts de l'élite parlementaire. Les députés de l'Assemblée contractuelle), Warszawa : Wydawnictwo IFiS PAN, pp. 229-260.

PAnkow I. (1993), "A Self-Portrait of the Polish Political Elite”, Sisyphus, n ${ }^{\circ}$, pp. 161-176.

PANKow I. (1994), Dysonans poznawczy politykow okresu transformacji (La dissonance cognitive des hommes politiques dans la période de transformation), in J. Wasilewski, wyd., Konsolidacja elit politycznych 1991-1993 (La consolidation des élites politiques 1991-1993), Warszawa : ISP PAN, pp. 163-183.

PANKow I. (1999), Zwiazki zawodowe a polityka (Les syndicats et les hommes politiques), in J. Wasilewski, wyd., Elita polityczna 1998. Raport wstepny z badan "Elita rzadzaca $i$ wladza elity" (L'élite politique 1998. Rapport liminaire de la recherche "L'élite gouvernante et l'élite du pouvoir"), Warszawa : ISP PAN, pp. 125-158.

PANKow I. \& Wesolowski W., wyd. (1995), Swiat elity politycznej (Le monde de l'élite politique), Warszawa : Wydawnictwo IFiS PAN.

Pawlak J. (1992), Podzialy w klubach poselskich (La répartition des députés dans les clubs parlementaires), in J. Wasilewski \& W. Wesolowski, wyd., Poczatki parlamentarnej elity. Poslowie kontraktowego Sejmu (Les débuts de l'élite parlementaire. Les députés de l'Assemblée contractuelle), Warszawa : Wydawnictwo IFiS PAN, pp. 97-117.

Pawlak J. (1994), Drogi do wladzy (Les chemins du pouvoir), in J. Wasilewski, wyd., Konsolidacja elit politycznych 1991-1993 (La consolidation des élites politiques 19911993), Warszawa : ISP PAN, pp. 93-106.

PaWlaK J. (1997), Polityczne korzenie nowej klasy politycznej (Les racines politiques de la nouvelle classe politique), in J. Wasilewski, Zbiorowi aktorzy polskiej polityki (Les acteurs collectifs de la politique polonaise), Warszawa : ISP PAN, pp. 303-335.

PoDgorecki A. (1994), "The Communist and Post-Communist Nomenklatura", Polish Sociological Review, $\mathrm{n}^{\circ}$ 2, pp. 111-123.

Polish Sociological Bulletin (1992), "The President Ask the Questions - the Sociologists Give their Advice", n 3-4.

Post B. (1992), Dylematy parlamentaryzmu w poselskich wizjach dobrego polityka (Les dilemmes parlementaristes dans les représentations des députés du bon homme politique), in J. Wasilewski \& W. Wesolowski, wyd., Poczatki parlamentarnej elity. Poslowie kontraktowego Sejmu (Les débuts de l'élite parlementaire. Les députés de l'Assemblée contractuelle), Warszawa : Wydawnictwo IFiS PAN, pp. 261-274.

Post B. (1994), Poselkie cnoty kurdynale $i$ grzechy glowne (Les vertus cardinales et les péchés capitaux des députés), in J. Wasilewski, wyd., Konsolidacja elit politycznych 19911993 (La consolidation des élites politiques 1991-1993), Warszawa : ISP PAN, pp. 185-200. 
Post B. (1995), Aktorzy polskiej sceny politycznej - amatorzy czy profesjonalisci ? (Les acteurs de la scène politique polonaise - amateurs ou professionnels ?), in I. Pankow \& W. Wesolowski, wyd., Swiat elity politycznej (Le monde de l'élite politique), Warszawa : Wydawnictwo IFiS PAN, pp. 199-217.

PosT B. (1997), Kobiety na politycznej scenie. Dylemati $i$ trudnosci (Les femmes sur la scène politique. Dilemmes et difficultés), in J. Wasilewski, Zbiorowi aktorzy polskiej polityki (Les acteurs collectifs de la politique polonaise), Warszawa : ISP PAN, pp. 225-245.

Post B. \& Wesolowski W., wyd. (1998), Polityka i Sejm. Formowanie sie elity politycznej (La politique et la Diète. La formation de l'élite politique), Warszawa : Wydawnictwo Sejmowe.

Przeor-Pastuszak I. \& Surmacz B. (1992), Percepcja polskiej elity politycznej w srodowisku akademickim politologow (La perception de l'élite politique polonaise dans les milieux universitaires politologiques), in K. Palecki, wyd., Elity polityczne w Polsce (Les élites politiques en Pologne), Warszawa : Zarzad Glowny Polskie Towarzystwo Nauk Politycznych, pp. 186-197.

SiEMIENSKA R. (2000), Nie moga, nie chca czy nie potrafia ? O postawach $i$ uczestnictwie politycznym kobiet $w$ Polsce (Ne peuvent-elles pas, ne veulent-elles pas ou sontelles incapables ? Les attitudes et la participation politique des femmes en Pologne), Warszawa : Wydawnictwo Naukowe "Scholar".

SKARZYNSKA K. (1996), Mlode elity polityczne. Charakterystyka psychologiczna (Les jeunes élites politiques. Caractéristiques psychologiques), Studia Psychologiczne, $\mathrm{n}^{\circ} 2$, pp. 45-59.

Skotnicka-Illasiewicz E. (1992), Drogi do Sejmu (Les chemins de la Diète), in J. Wasilewski \& W. Wesolowski, wyd., Poczatki parlamentarnej elity. Poslowie kontraktowego Sejmu (Les débuts de l'élite parlementaire. Les députés de l'Assemblée contractuelle), Warszawa : Wydawnictwo IFiS PAN, pp. 157-191.

Skotnicka-Illasiewicz E. (1995), Polska w Europie - odmienne wizje (La Pologne en Europe - des visions différentes), in I. Pankow \& W. Wesolowski, wyd., Swiat elity politycznej (Le monde de l'élite politique), Warszawa : Wydawnictwo IFiS PAN, pp. 81-107.

StOBINSKA K. (1994), Elity polityczne wobec dylematow transformacji (Les élites politiques face aux dilemmes de la transformation), in J. Wasilewski, wyd., Konsolidacja elit politycznych 1991-1993 (La consolidation des élites politiques 1991-1993), Warszawa : ISP PAN, pp. 107-127.

STOBINSKA K. (1995), Transformacja gospodarki - obszar porozumienia czy konfrontacji? (La transformation de l'économie - un espace d'entente ou de confrontation ?), in I. Pankow \& W. Wesolowski, wyd., Swiat elity politycznej (Le monde de l'élite politique), Warszawa : Wydawnictwo IFiS PAN, pp. 235-251.

Szelenyi I. \& Szelenyi S. (1995), "Circulation or Reproduction of Elites during the Postcommunist Transformation of Eastern Europe. Introduction", in Theory and Society, Special Issue on Circulation vs. Reproduction of Elites during the PostCommunist Transformation on Eastern Europe, $n^{\circ} 5$, pp. 615-638.

Szelenyi I., Treiman D. \& Wnuk-Lipinski E., wyd. (1995), Elity w Polsce, w Rosji i na Wegrzech. Wymiania czy reprodukcja? (Les élites en Pologne, Russie et Hongrie. Changement ou reproduction ?), Warszawa : ISP PAN.

TARAS R. (1998), "The Politics of Leadership", in S. White, J. Batt \& P. G. Lewis, Developments in Central and East European Politics, Durham : Duke University Press, pp. 103-125.

Theory and Society (1995), Special Issue on Circulation vs. Reproduction of Elites during the Post-Communist.Transformation on Eastern Europe, $n^{\circ} 5$. 
Wasilewski J. (1992), "The Contract-based Diet and Elite Formation in Poland", The Polish Sociological Bulletin, $\mathrm{n}^{\circ}$ 2, pp. 41-47.

WASILEWSKi J., wyd. (1994a), Konsolidacja elit politycznych 1991-1993 (La consolidation des élites politiques 1991-1993), Warszawa : ISP PAN.

WASILEWSKI J. (1994b), “La nomenklatura : vers quel destin social ?", Revue d'études comparatives Est-Ouest, vol. 25, n 4, pp. 33-46.

WASILEwski J. (1995a), "The Crystallization of the Post-Communist and Post-Solidarity Political Elite", in E. Wnuk-Lipinski, Ed., After Communism, a Multidisciplinary Approach of Radical Social Change, Warszawa : PAN-ISP, pp. 117-133.

WASILEwSKI J. (1995b), "The Forming of the New Elite: How Much Nomenklatura is Left?", Polish Sociological Review, n², pp. 113-124.

Wasil.ewski J. (1996), Badania nad elitami w Polsce : 1989-1995 (Les études sur les élites politiques en Pologne : 1989-1995), in K. Gorlach \& Z. Serega, Oblicza $i$ spoleczenstwa (Visages de la société), Krakow: Uniwersytet Jagiellonski, pp. 219-236.

WASILEWSKI J., wyd. (1997a), Zbiorowi aktorzy polskiej polityki (Les acteurs collectifs de la politique polonaise), Warszawa : ISP PAN.

WASILEWSKI J. (1997b), Orientacje wartosciujace elity : plytka konsolidacja polskiej demokracji (Les orientations et les valeurs de l'élite : la consolidation fragile de la démocratie polonaise), in J. Wasilewski, Zbiorowi aktorzy polskiej polityki (Les acteurs collectifs de la politique polonaise), Warszawa : ISP PAN, pp. 273-302.

WASILEWSKI J. (1998), "Elite Circulation and Consolidation of Democracy in Poland", in J. Highley, J. Pakulski \& W. Wesolowski, Postcommunist Elites and Democracy in Eastern Europe, New York : St. Martin's Press, pp. 163-187.

WASILEWSKI J., wyd. (1999a), Elita polityczna 1998. Raport wstepny z badan "Elita rzadzaca $i$ wladza elity" (L'élite politique 1998. Rapport liminaire de la recherche "L'élite gouvernante et l'élite du pouvoir"), Warszawa : ISP PAN.

WASILEWSKI J. (1999b), Socjologiczny portret polskiej elity po transformacyjnej (Le portrait sociologique de l'élite politique de la transformation), in J. Wasilewski, wyd., Elita polityczna 1998. Raport wstepny z badan "Elita rzadzaca i wladza elity" (L'élite politique 1998. Rapport liminaire de la recherche "L'élite gouvernante et l'élite du pouvoir”), Warszawa : ISP PAN, pp. 23-44.

WASILEWSKi J. \& Wesolowski W., wyd. (1992), Poczatki parlamentarnej elity. Poslowie kontraktowego Sejmu (Les débuts de l'élite parlementaire. Les députés de l'Assemblée contractuelle), Warszawa : Wydawnictwo IFiS PAN.

WASILEWSKI J. \& WNUK-LIPINSKI E. (1995), "Poland. Winding Road from the Communist to the Post-Solidarity Elite", in Theory and Society, Special Issue on Circulation vs. Reproduction of Elites during the Post-Communist Transformation on Eastern Europe, ${ }^{\circ}$ 5, pp. 669-696.

Wesolowski W. (1992), "The Role of Political Elites in Transition from Communism to Democracy. The Case of Poland", Sisyphus, n² 2, pp. 77-100.

WESOlowsKI W. (1995), Rozumienie polityki wsrod politykow (La compréhension du politique parmi les hommes politiques), in I. Pankow \& W. Wesolowski, wyd., Swiat elity politycznej (Le monde de l'élite politique), Warszawa : Wydawnictwo IFiS PAN, pp. 111-167.

Wesolowski W. (1999), "Theoretical Aspects of Elite Research in Post-Communist Societies", communication au workshop « The Second Generation of Democratic Elites in Eastern and Central Europe ", Mogilany, 10-12 décembre.

WiATR J. J. (1995), "The Dilemmas of Re-organizing the Bureaucracy in Poland during the Democratic Transformation", Communist and Post-Communist Studies, $\mathrm{n}^{\circ} 1$, pp. 153-160.

ZubeK V. (1997), “The Eclipse of Walesa's Political Career”, Europe-Asia Studies, Vol. $49, \mathrm{n}^{\circ} 1$, pp. 107-124. 


\section{Élites locales}

BARTKOWski J. (1992), Kariery dzialaczy lokalnych. Systemowe mechanizmy selekcji w latach osiemdziesiatych (Les carrières des militants locaux. Les mécanismes systémiques de sélection dans les années quatre-vingt), Warszawa : Instytut Socjologii - Uniwersytet Warszawski.

BARTKOwski J. (1996), Lokalne elity wladzy w Polsce $w$ latach 1966-1995 (Les élites du pouvoir local en Pologne entre 1955 et 1966), Warszawa : Interart.

Bukowski A. (1996), "Citizens' Committees in the Process of Formation of Local Power: A Polish Case Study", in J. Gibson \& P. Hanson, Eds., Transformation from Below. Local Power and the Political Economy of Post-Communist Transition, Cheltenham : Edward Elgar Publishing Company, pp. 145-161.

Heurtaux J. (1998), "La question du renouvellement de l'élite politique polonaise : l'exemple de la voïevodie de Katowice", L'autre Europe, n' 36-37, pp. 178-202.

Jasinska-Kania A. (1986), "Comparative Studies on Local Political Leadership", in J. J. Wiatr, Ed., Local Politics in Poland. Twenty Years of Research, Warsaw : Institute of Sociology, pp. 13-32.

JASINSKA-KANIA A. (1998), Kim sa przedstawiciele lokalnych elit wladzy? (Qui sont les représentants locaux de l'élite du pouvoir ?), in J. J. Wiatr, wyd., Wladza lokalna w warunkach demokracji. Raport z badan (Le pouvoir local dans les conditions démocratiques. Rapport de recherches), Warszawa : Wydawnictwo Naukowe "Scholar", pp. 35-45.

JASINSKA-KANia A. \& Siemienska R. (1982), "Attitudes of Local Authorities Prior to the Crisis of 1980", in J. J. Wiatr, Ed., Local Politics in Poland. Twenty Years of Research, Warsaw : Institute of Sociology, pp. 172-189.

JASINSKA-KANIA A. \& WIATR J. J. (1986), "Polish Local Leaders in New Realities", in J. J. Wiatr, Ed. The Politics of Democratic Transformation : Poland after 1989, Warsaw : Scholar Agency, pp. 57-79

LYSON W. (1994), Liderzy nowej wladzy lokalnej (Les leaders du nouveau pouvoir local), in P. Dobrowolski, wyd., Wladza i spolecznosci lokalne w procesie przeobrazen ustrojowych (Pouvoir et société locaux dans le processus de transformation du système), Katowice : Wydawnictwo Uniwersytetu Slaskiego, pp. 102-106.

Ostrowski K. \& Przeworski A. (1986), "Local Leadership in Poland", in J. J. Wiatr, Ed., Local Politics in Poland. Twenty Years of Research, Warsaw : Institute of Sociology, pp. 33-65.

Pietrzko B. (1994), Wizerunek lidera lokalnego (Le portrait du leader local), in P. Dobrowolski \& L. Frackiewicz, wyd., Polityczne i spoleczne problemy gminy (Problèmes politiques et sociaux de la commune), Katowice : Wydawnictwo Uniwersytetu Slaskiego, pp. 28-38.

Siemienska R. (1983), "Local Party Leaders in Poland", International Political Science Review, $\mathrm{n}^{\circ} 1$, pp. 127-136.

SIEMIENSKA R. (1986a), "Local Leaders' Hierarchy of Values and their Model of a 'Good Leader"', in J. J. Wiatr, Ed., Local Politics in Poland. Twenty Years of Research, Warsaw : Institute of Sociology, pp. 207-224.

SIEMIENSKA R. (1986b), "Popular Demands and Leadership Responses in Periods of Economic Retrait", in J. J. Wiatr, Ed., Local Politics in Poland. Twenty Years of Research, Warsaw : Institute of Sociology, pp. 225-249.

SiEMIENSKA R. \& TARKowski J. (1986), "Polish Local Leaders and Fulfilling Community Needs: Politicians and Administraturs", in J. J. Wiatr, Ed., Local Politics in Polund. Twenty Years of Research, Warsaw : Institute of Sociology, pp. 143-171. 
SzTUMSKI J., wyd. (1995), Elity w procesie transformacji spoleczno-gospodarczej $i$ politycznej Polski (Les élites dans le processus de transformation socio-économique et politique en Pologne), Katowice : Wydawnictwo Uniwersytetu Slaskiego.

TARKowsKi J. (1978), "Local Influences in a Centralized System. Ressources, Local Leadership and Integration in Poland", in J. J. Wiatr, Ed. Local Politics in Poland. Twenty Years of Research, Warsaw : Institute of Sociology, pp. 91-142.

TARKowski J. (1981), "Determinants of Local Influence”, Polish Political Science Yearbook.

TARKOWSKI J., WIATR J. J. \& ZAJORSKI K. (1972), Radni i czlonkowie prezydiow rad narodowych 1958-1969 (Les conseillers et les membres du présidium des conseils nationaux 1958-1969), Warszawa : Glowny Urzad Statystyczny PRL.

WASILEWSKI J. (1990b), Spoleczne procesy rekrutacji regionalnej elity wladzy (Les processus sociaux du recrutement de l'élite du pouvoir régional), Warszawa : Wydawnictwo Polskiej Akademii Ossolinskich.

WIATR J. J. (1967), Gospodarcze terenu. Z socjologicznych badan nad aktywem powiatowym (L'économie des territoires. Sur les recherches sociologiques consacrées aux responsables des powiats), Nowe Drogi, $\mathrm{n}^{\circ} 1$, pp. 55-65.

Wiatr J. J. (1986), Ed., Local Politics in Poland. Twenty Years of Research, Warsaw : Institute of Sociology.

Wiatr J. J., wyd. (1987c), Wladza lokalna w warunkach kryzysu (Le pouvoir local dans les circonstances de crise), Warszawa : Uniwersytet Warszawski - Instytut Socjologii.

Wodz J. (1999), "The New Local Elite in Poland. The Dynamics of Change (Some Results of Empirical Research in Upper Silesia)", in J. Wodz, Ed., Local Power and Modern Community Political Life. Sociological Essays, Katowice : Wydawnictwo Uniwersytetu Slaskiego, pp. 75-85.

Wodz J. \& Wodz K. (1996), "Les acteurs de la vie politique locale en Pologne. 1990-95. Quelques réflexions socio-politiques", in J. Petaux \& J. Wodz, dir., Les acteurs de la vie politique locale, Katowice : Slask, pp. 23-36.

\section{Autres}

Bailey F. G. (1971), Les règles du jeu politique, Paris : Presses Universitaires de France.

Blondiaux L. (1997), "Les tournants historiques de la science politique américaine". Politix, $\mathrm{n}^{\circ}$ 40, pp. 7-38.

BotTomore T. B. (1964), Élites et société, Paris : Stock.

Derrida J. (1995), Moscou aller-retour, Paris : Editions de l'aube.

Burton M. G. \& Higley J. (1989), "The Elite Variable in Democratic Transitions and Breakdowns", American Sociological Review, $\mathrm{n}^{\circ}$ 54, pp. 17-32.

Gunther R. \& Higley J. (1992), Elites and Democratic Consolidation in Latin America and Southern Europe, Cambridge : Cambridge University Press.

Lagrave R.-M. (1998), Voyage aux pays d'une utopie déchue, Paris : Presses Universitaires de France.

LAGROYE J. (1984), "La légitimation", in Traité de science politique, tome 1, Paris : Presses Universitaires de France, pp. 395-467.

LÉVÊQUE S. (1996), “'L'entrée en politique'. Bibliographie sur les conditions sociales de la professionnalisation et de la 'réussite' politique en France", Politix, 35, pp. 171-187.

LudTKE A. (1998), "La République Démocratique Allemande comme histoire. Réflexions historiographiques", Annales Histoire, Sciences sociales, n ${ }^{\circ} 1$, pp. 3-39.

Mills C. W. (1969), L'élite du pouvoir, Maspero : Paris. 
MiNK G. \& SZUREK J.-C. (1994c), "Paradigmes sociologiques : héritages et nouveaux questionnements", Revue d'études comparatives Est-Ouest, n ${ }^{\circ} 4$, vol. 25, pp. 5-13.

OfFERLE M., dir. (1999), La profession politique XIXe-XXe siècles, Paris : Belin.

Podgorecki A. (1991b), "Le cas d'une sociologie aliénée, témoin et acteur d'un changement social global", Revue d'études comparatives est-ouest, vol. XXII, n 1 , pp. 123140.

Polish Sociological Review (1998), "Polish Sociology Under Communism", n 2.

Politologia $w$ szkolnictwie wyzszym $w$ Polsce. Studia $i$ materialy (La politologie dans l'enseignement supérieur en Pologne. Études et matériaux) (1997), Lublin : Wydawnictwo UMCS.

Putnam R. (1976), The Comparative Study of Political Elites, Prentice-Hall, N.J. : Englewood Cliffs.

SAWICKI F. (1999), "Classer les hommes politiques. Les usages des indicateurs de position sociale pour la compréhension de la professionnalisation politique", in $\mathbf{M}$. Offerlé, dir., La profession politique XIXe-XXe siècles, Paris : Belin, pp. 135-170.

SMith R. M. (1997), "La quête américaine d'une science politique démocratique et scientifique", Politix, n 40 , pp. 58-87. 